

\section{DISCLAIMER}

This report was prepared as an account of work sponsored by an agency of the United States Government. Neither the United States Government nor any agency Thereof, nor any of their employees, makes any warranty, express or implied, or assumes any legal liability or responsibility for the accuracy, completeness, or usefulness of any information, apparatus, product, or process disclosed, or represents that its use would not infringe privately owned rights. Reference herein to any specific commercial product, process, or service by trade name, trademark, manufacturer, or otherwise does not necessarily constitute or imply its endorsement, recommendation, or favoring by the United States Government or any agency thereof. The views and opinions of authors expressed herein do not necessarily state or reflect those of the United States Government or any agency thereof. 


\section{DISCLAIMER}

Portions of this document may be illegible in electronic image products. Images are produced from the best available original document. 
This is the second report in this series. The first report, unclassified, is LA-9198-PR.

This work was supported by the US Department of Energy, Division of Advanced Nuclear Systems and Projects.

\section{DISCLAIMER}

This report was prepared as an account of work sponsored by an agency of the United States Government. Neither the United States Government nor any agency thereof, nor any of their employees, makes any warranty, express or implied, or assumes any legal liability or responsibility for the accuracy, completeness, or usefulness of any information, apparatus, product, or process disclosed, or represents that its use would not infringe privately owned rights. References herein to any specific commercial product, process, or service by trade name, trademark, manufacturer, or otherwise, does not necessarily constitute or imply its endorsement, recommendation, or favoring by the United States Government or any agency thereof. The views and opinions of authors expressed herein do not necessarily state or reflect those of the United States Government or any agency thereof. 


\title{
Space Reactors
}

\author{
April-June 1981 \\ Prepared by \\ William A. Ranken \\ Space Reactors Project Leader
}

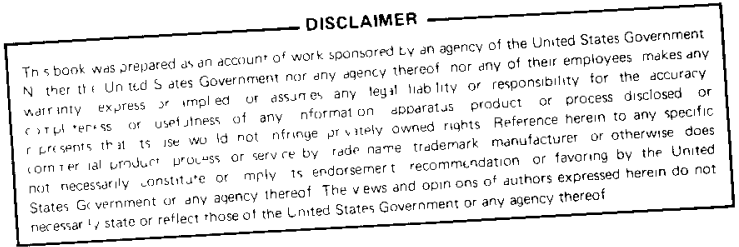

NOTICE

PORTIONS OF THIS REPORT ARE ILLEGIBLE. It

has been reprodised from the best available

cony to permit the broadest possible avail-

ability.

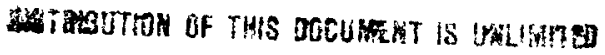
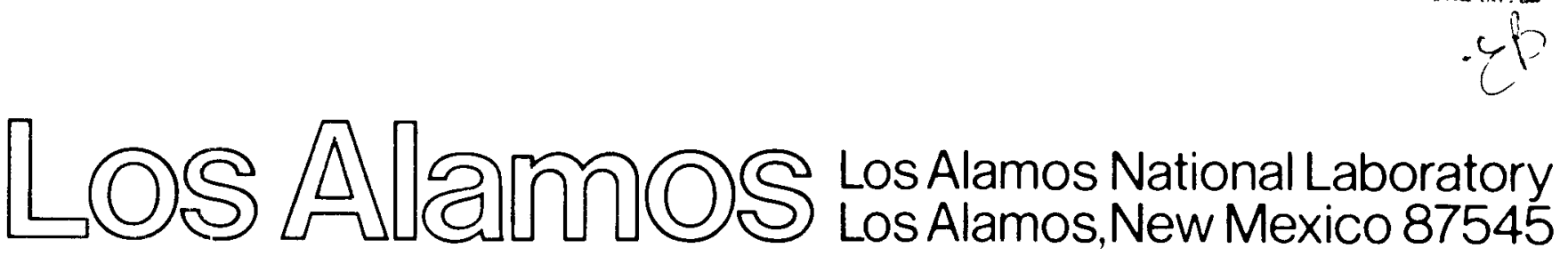
SPACE REACTORS

Apri T-June 1981

Prepared by

William A. Ranken

Space Reactors Project Leader

\begin{abstract}
Significant progress has been made in the Space Reactors design and experimental programs. Further analysis of the space reactor reactivity has shown that 2 to $3 \mathrm{~kg}$ of $\mathrm{B}_{4} \mathrm{C}$ must be evenly distributed throughout the core to prevent criticality in the case of water immersion. A new core heat pipe processing, filling, and confirmatory testing system has significantly reduced the time required for these operations. The first dual-artery molybdenum/sodium heat pipe has been fabricated successfully. Fabrication of the in-pile test capsules and fuel tiles has begun. Experiments to develop methods of strengthening wicks and reducing wick pore size through chemical vapor deposition have yielded good results using tungsten. Thermoelectric couple redesign for fabrication and assembly methods prove-in has been completed, as has the test facility for these units.
\end{abstract}




\section{EXECUTIVE SUMMARY (W. A. Ranken, Q-13)}

Components for a $10-$ to $100-k w_{e}$ space nuclear reactor electric power plant are being designed, fabricated, and tested. Such a power plant will consist of (1) a nuclear reactor for generating heat, including heat pipes for transferring the energy from the reactor to the power conversion equipment; (2) a radiation shield to attenuate radiation to an acceptable level for the payload; (3) thermoelectric (TE) converters to convert heat to electricity; and (4) a radiator for rejecting waste heat to space. The components being designed and tested, when incorporated into a power plant, will provide a power source for nuclear electric propulsion systems being developed by NASA for missions to study the outer planets, as well as a relatively inexpensive, compact power source for large, earth-orbiting satellites, which the Department of Defense is evaluating for communication and surveillance.

Significant results have been obtained in the design and experimental programs, as follows.

Further analysis of the reactivity increment of the SPAR reactor, for water immersion causing the heat pipes to fill with water, has shown that removable enriched $B_{4} C$ absorbers at the cylindrical periphery of the core will not be sufficient to prevent criticality. A more even distribution of 2 to 3 $\mathrm{kg}$ of $\mathrm{B}_{4} \mathrm{C}$ throughout the core will be required.

- A new core heat pipe processing, filling, and confirmatory testing system has been built that has reduced total time for these operations from 1 month to 1 week. Two molybdenum/sodium heat pipes have been assembled and successfully put through preliminary tilt testing with this apparatus.

- The first dual-artery molybdenum/sodium heat pipe has been fabricated. Pending development of fine-mesh molybdenum screen, this unit was assembled with available 150 mesh screen to develop fabrication procedures; hence, its performance will not be up to SPAR reference design requirements. Preliminary testing showed satisfactory, gas-free operation, although there is indication of relatively high flow impedance for fluid moving from the arteries to and/or through the distribution wick.

- Fabrication of $\mathrm{UO}_{2}$ fuel tiles and other components of the SPAR fuel irradiation capsules has been initiated. Three enrichments of ${ }^{235} \mathrm{U}$ will be used in the capsule to provide different rates of test acceleration in the 
EBR-II. A gas-filled heat pipe is being developed for temperature control of the experiment.

Experiments to develop methods of strengthening wicks and reducing wick pore size by chemical vapor deposition of tungsten have yielded a 300-mmlong specimen of screen tube with very uniform and stable deposit. Pore size was reduced from $190 \mu \mathrm{m}$ to $110_{\mu \mathrm{m}}$.

- Redesign of the thermoelectric couple for fabrication and assembly methods prove-in has been completed, and these couples are being fabricated. The test facility for these units has been completed, and furnaces for the thermoelectric module component testing program are being installed.

II. MISSION REQUIREMENTS (D. Buden, DAD/NP)

Further refinement was made of the proposed Nuclear Safety Guidelines for the Use of Fisson Reactors in Space. Compliance with these guidelines in the reactor design will ensure that the interaction of radioactive materials with humans and the environment will be limited to a safe level. All modes of safety philosophy will be used to meet safety standards including:

(1) confine and contain to isolate the radioactive material from the population by barriers;

(2) delay and decay to provide for sufficient isolation time so that radioactive levels are reduced to meet safety standards before exposure to the population (this can be accomplished in space missions of long-life orbits on the order of $300 \mathrm{yr}$ or more); and

(3) disperse when there is a large medium for dispersal such that elements in the population are not exposed to radiation levels greater than set forth in the radiological standards.

Confine and contain will be used prior to launch and during launch as a safety scheme. Delay and decay will be used in orbit operation, while disperse will be used on atmospheric re-entry.

The paper "Reactors for Nuclear Electric Propulsion" by D. Buden and J. A. Angelo, AIAA-81-0697, was presented at the International Electric Propulsion Conference, Las Vegas, April 21-23. The paper points out that propulsion is the key to space exploitation and power is the key to 
propulsion. The role of nuclear fission reactors as the primary power source for high specific impulse electric propulsion systems for space missions of the 1980s and 1990s is examined. Particular mission applications include transfer to and a reusable orbital transfer vehicle from low-Earth orbit to geosynchronous orbit, outer planet exploration and reconnaissance missions, and as a versatile space tug supporting lunar resource development. Nuclear electric propulsion is examined as an indispensable component in space activities of the next two decades.

Other areas of activity included support of the Space Power Working Group, support of Integrated Tactical Surveillance System studies, review of rotating bed reactors, and initiation of preparation of a joint NASA/DOE program plan.

\section{POWER PLANT SYSTEM}

\section{A. SPAR Water Immersion Studies (R. G. Palmer, Q-13).}

With natural boron in the SPAR reactor control drums, the reactivity swing between in and out positions will be about $7.7 \% \Delta k / k$. Reactivity requirements for going to full power and for $7-y r$ burnup would be about $3.2 \% \Delta k / k$. Thus, the design $k_{\text {eff }}$ for the reactor in a cold and fresh shutdown state would be about 0.955 .

Should the reactor fall into the ocean or a lake and water enter the heat pipes, the calculated $k_{\text {eff }}$ would $r$ ise to 1.10 due to the large reduction of neutron leakage from the core. In practice, the $k_{\text {eff }}$ could not go this high without destroying the reactor. To preclude the possibility of a supercritical state, the core would have to be loaded with 2 to $3 \mathrm{~kg}$ of enriched boron carbide, which would have to be removed once a safe orbit is reached.

Attempts to minimize the impact on the core design by placing absorber segments at the edge of the core did not succeed because of the low neutron importance at the edge, and because edge absorbers enhance the increase in reactivity resulting from decreased neutron leakage from the main body of the core. To make an intact reactor subcritical in water will require the enriched $B_{4} C$ to be distributed more evenly throughout the core.

1. Supersystem Studies. The only system code currently available for SPAR is one that considers only the reactor. A task has been started on developing 
a supersystem code that incorporates all of the subsystems: reactor, shield, electric converters, radiator, and payload. At the moment, a series of "generic" shielding calculations is being performed to get shield mass for both neutrons and photons as a function of reactor power, radiator half-angle, and payload radiation constraints.

2. Photon Shielding for SPAR. A "back-of-the-envelope" calculation showed that the $\mathrm{LiH}+$ SS structure in the SPAR shield was sufficient to reduce the gamma dose to less than $10^{7} \mathrm{rad}$ in $7 \mathrm{yr}$. MCNP photon shielding studies are now under way to confirm this. A MCNP coupled neutron-gamma criticality case has been completed to obtain the gamma source for the shielding studies.

B. In-Pile Test of SPAR Fuel (J. T. Sena, A. J. Giger, E. S. Keddy, L. A. Hiteman, R. G. Palmer, M. G. Elder, Q-13).

1. General. A SPAR fuel in-pile test is planned for Argonne National Laboratory's (ANL) EBR-II reactor in Idaho Falls. Technical feasibility has been established with ANL for the experiment and the request for Approval-inPrinciple has been submitted to the Reactor Research Technology Division of DOE.

The experiment, to be supported within an ANL MK M-1A irradiation subassembly, is designed to provide early data on SPAR fuel swelling. In addition, information will be sought on heat transfer between fuel, fin, and heat pipe; fuel migration; heat pipe performance; and chemical compatibility of fuel, fin, and heat pipe materials.

2. Design. Several changes have been made to the design presented in the last progress report. A 3.6-mm-thick hemispherical bottom has been added to the vacuum plenum in which the fuel is contained in order to control the unlikely case of a fuel melt. The condenser section of the heat pipe used to cool the fuel specimens has been lengthened to allow for reduced heat transfer through the threaded section. Fill-tube details were revised, and the stainless steel external flow guide that channels the reactor coolant past the heat pipe condenser section has been perforated and provided with baffles to allow for post-test removal of sodium. Most of the detail drawings for experimental parts have been completed. 
3. Analysis. Proper operation of the temperature control feature of the gas-filled heat pipe that cools the $\mathrm{UO}_{2}$ fuel wafers depends on adequate radial thermal conductance from the threaded condenser section to the EBR-II sodium coolant. An analytical model has been developed to study the effect of thread contact and thread gap resistance variations on the heat removal capability of the condenser section. Figure 1 is a plot of the condensing capability of this section versus thread contact for a heat pipe temperature of 1400 $\mathrm{K}$ and EBR-II sodium coolant temperature of $771 \mathrm{~K}$. A conservative value of thread contact should be between $0.1 \%$ and $1.0 \%$, with a thread gap of $.05 \mathrm{~mm}$. These data were used to select a value of $1.25 \mathrm{~kW} / \mathrm{cm}$ for the design. Calibration testing of the heat pipe will provide one or more experimental data points for verification.

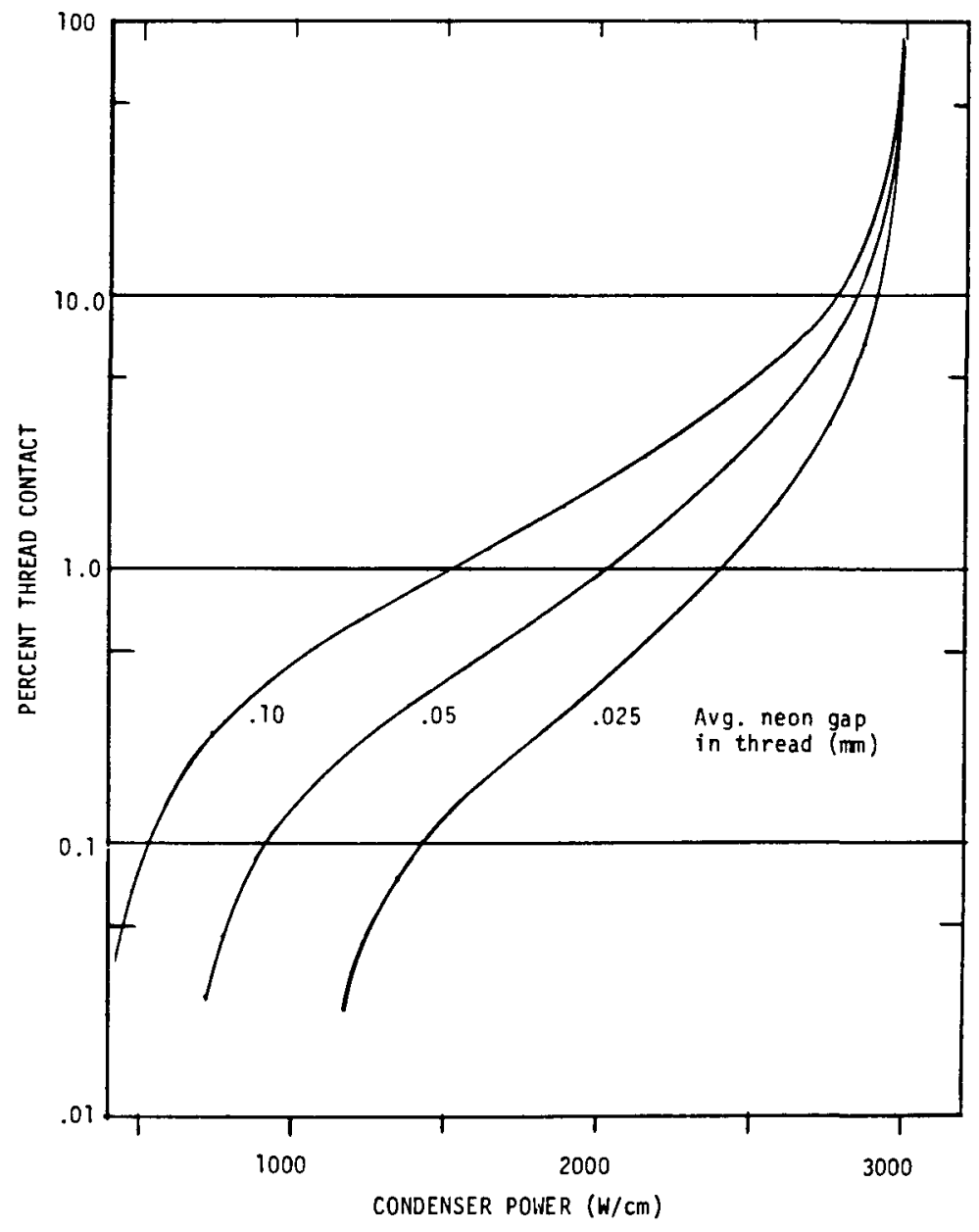

Fig. 1. Effect of thread contact on heat removal capability in the SPAR fuel experiment condenser section. 
Two interrelated areas still undergoing analysis are the fuel section of the experiment and the bottom of the vacuum plenum. The unlikely scenario that relates these is the functional loss of the heat pipe coupled with an inability of the fuel container to rid itself of fission and gamma heating, with subsequent melting of the molybdenum container, $\mathrm{UO}_{2}$ fuel and $\mathrm{ZrO}_{2}$ insulation, and with these materials falling into the heavy-walled bottom of the niobium vacuum bottle.

The Ayer heat transfer modeling code has been used to model the bottom of the vacuum bottle as shown in Fig. 2. This model was used to examine the transient behavior of the temperature of the niobium wall and the sodium bond to the outer stainless steel shell for the case of fuel meltdown. Figure 3 , taken at section A-A of Fig. 2, gives the temperature distributions from $1 \mathrm{~s}$ to $6 \mathrm{~s}$ after the fuel has instantaneously appeared in a molten condition in the bottom of the vacuum bottle, with a temperature of $2800 \mathrm{~K}$. This computation showed that temperatures at the niobium interface were already decreasing with time as soon as $1 \mathrm{~s}$ after the meltdown event. This result is amplified by Fig. 4, which shows the temperature profiles through the same section for times from $.025 \mathrm{~s}$ to $1.2 \mathrm{~s}$.

In making this calculation, smeared properties were assumed for the melt. The niobium bottle, sodium bond, and stainless steel outer shell temperatures were set at the EBR-II sodium coolant temperature, $771 \mathrm{~K}$. Heat of fusion effects were included, as were variable material properties.

The model was used to determine a niobium wall thickness such that the vapor pressure of the sodium bond did not exceed $1.5 \times 10^{5} \mathrm{~N} / \mathrm{m}^{2}$. Maximum temperature of the sodium bond vs time is shown in Fig. 5. Maximum temperature of a 3.6-mm-thick niobium bottle was determined to be $1479 \mathrm{~K}$ at $1.2 \mathrm{~s}$.

Analysis of the fuel region has begun. It is based on the axisymmetric model shown in Fig. 6. This represents a section from the heat pipe center line radially outward to the EBR-II sodium coolant. Axially, it extends from the middle of one fuel test bay to the middle of the next, and contains the $\mathrm{ZrO}_{2}$ insulating washers located between the test bays. Boundaries allow analysis of radial and axial heat flow.

Figure 7 shows the temperature distributions for a nominal case with both molybdenum fuel container and niobium capsule wall emissivities of .21. No interface resistance between fuel and the insulating sleeve is present, however. 


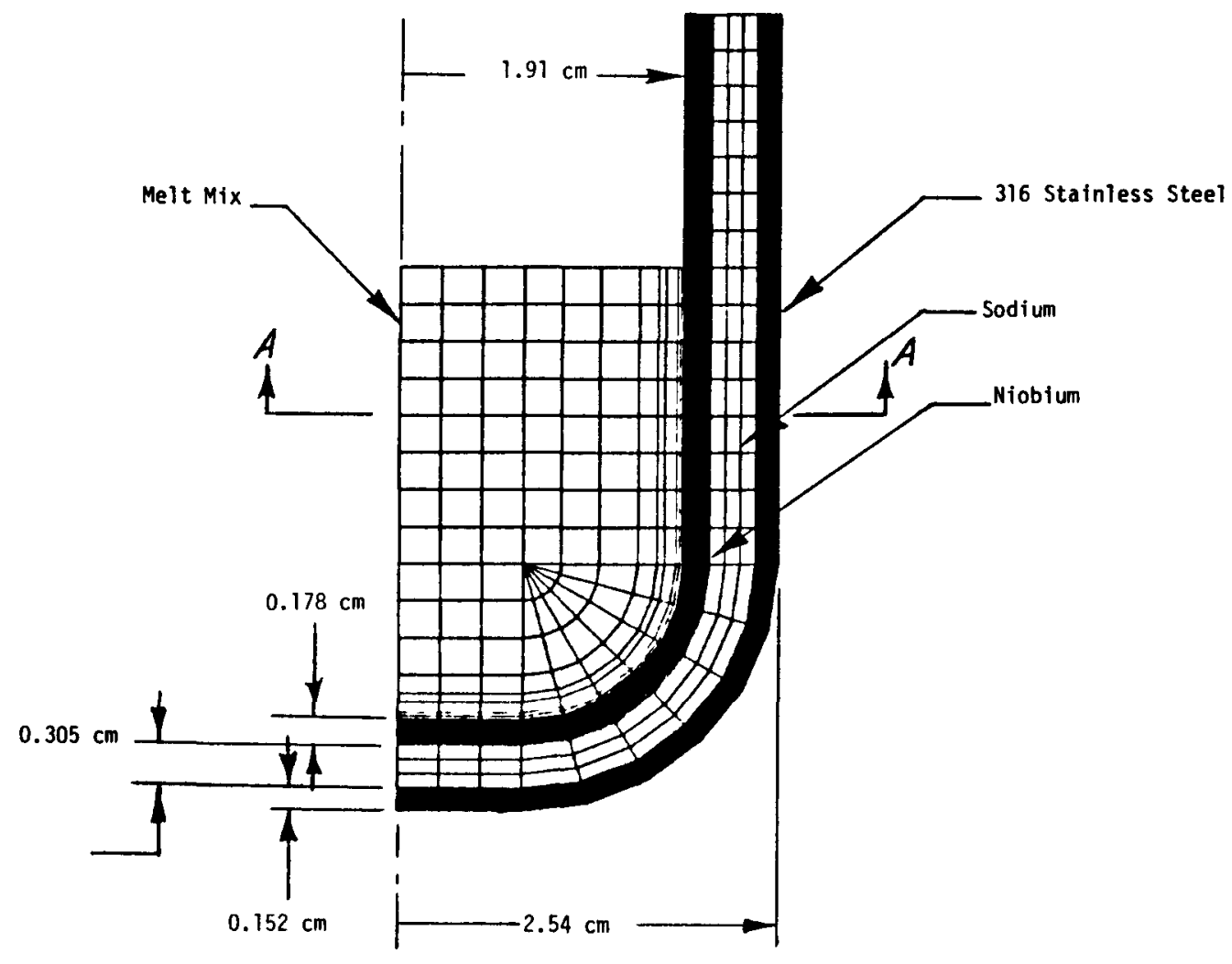

Fig. 2. Analytical model of vacuum bottle heat transfer.

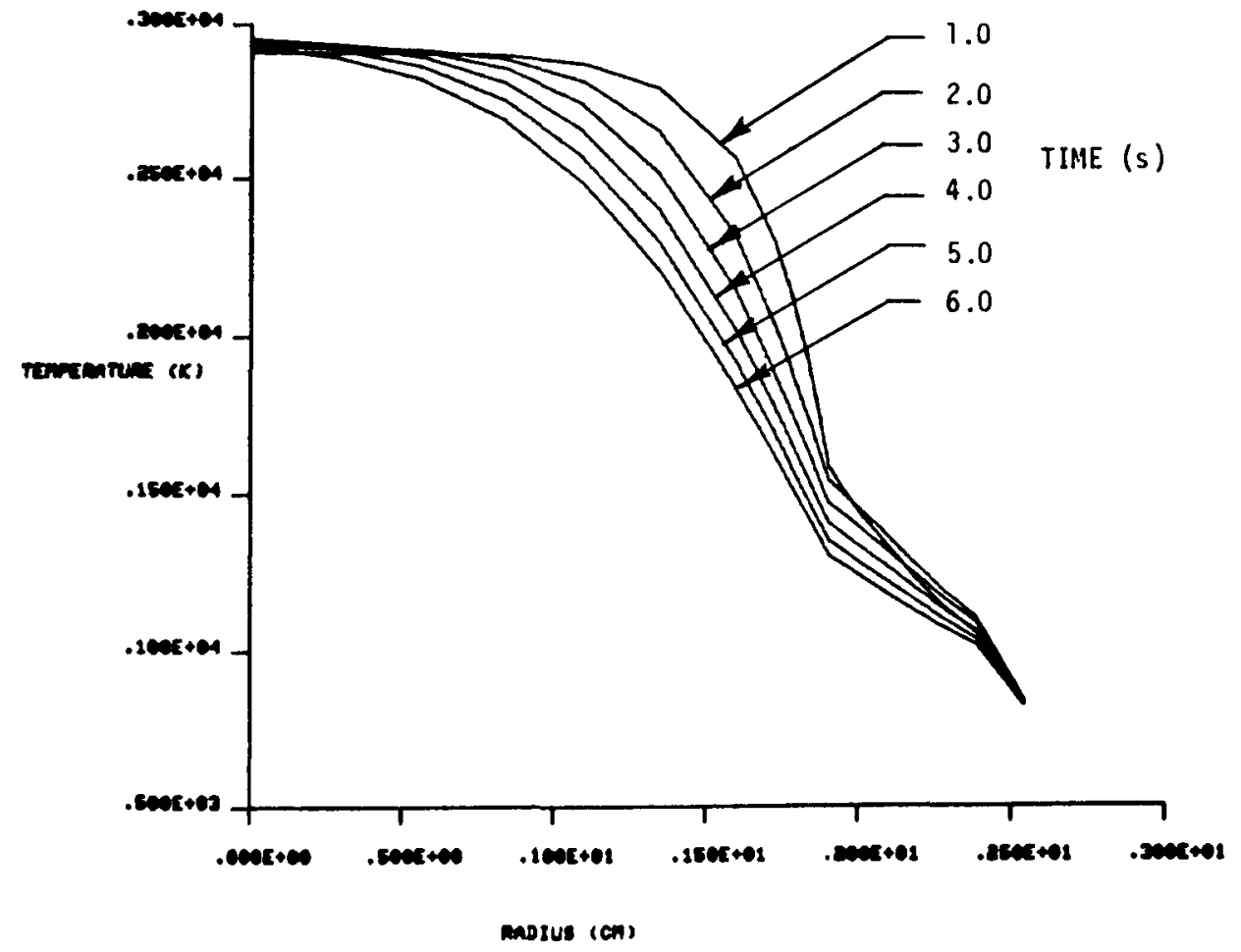

Fig. 3. Analytical model showing temperature distributions in vacuum bottle 1 to $6 \mathrm{~s}$ after fuel meltdown. 


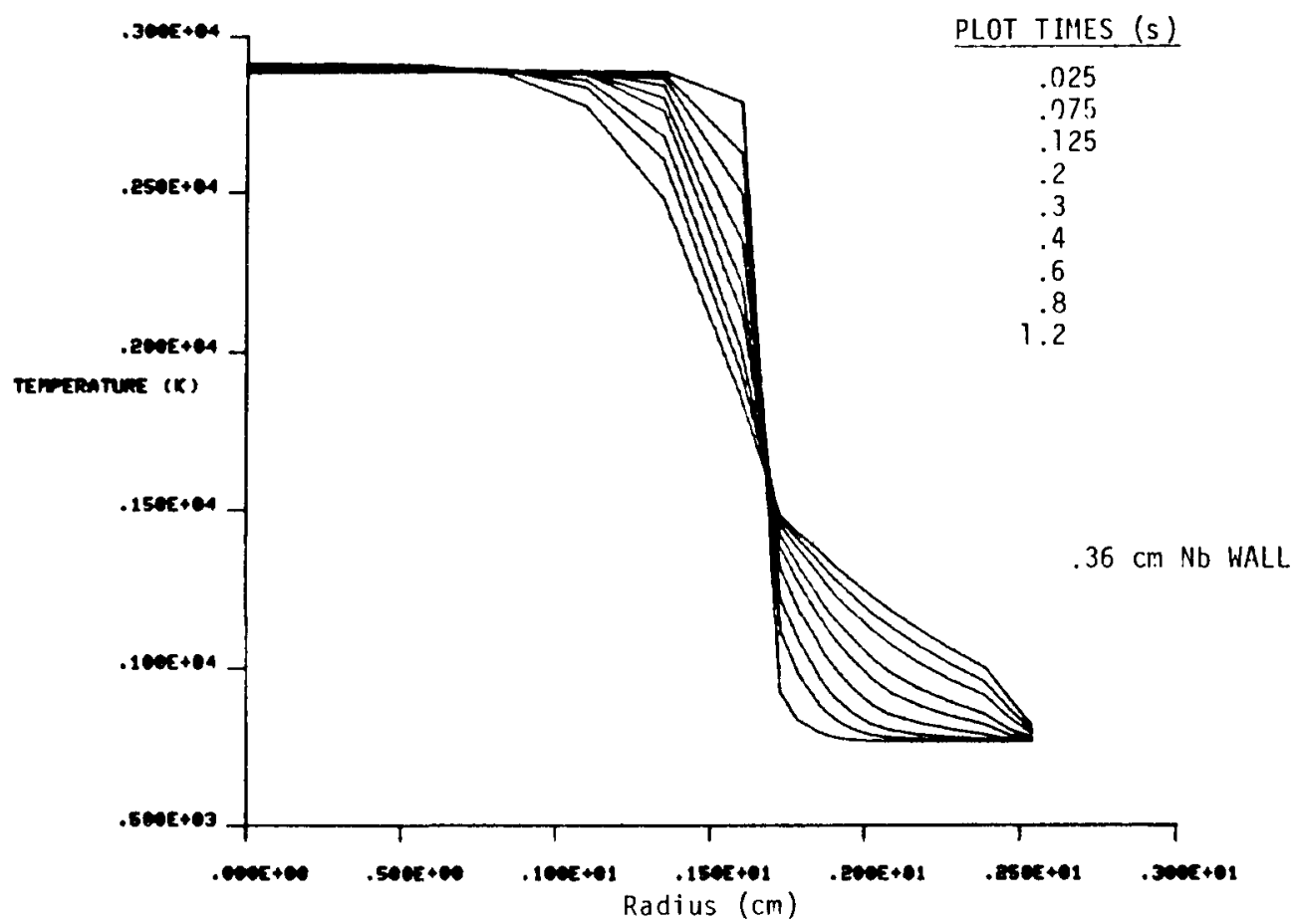

Fig. 4. Analytical model showing temperature profiles trirough section of vacuum bottle .025 to $1.2 \mathrm{~s}$ after fuel meltdown.

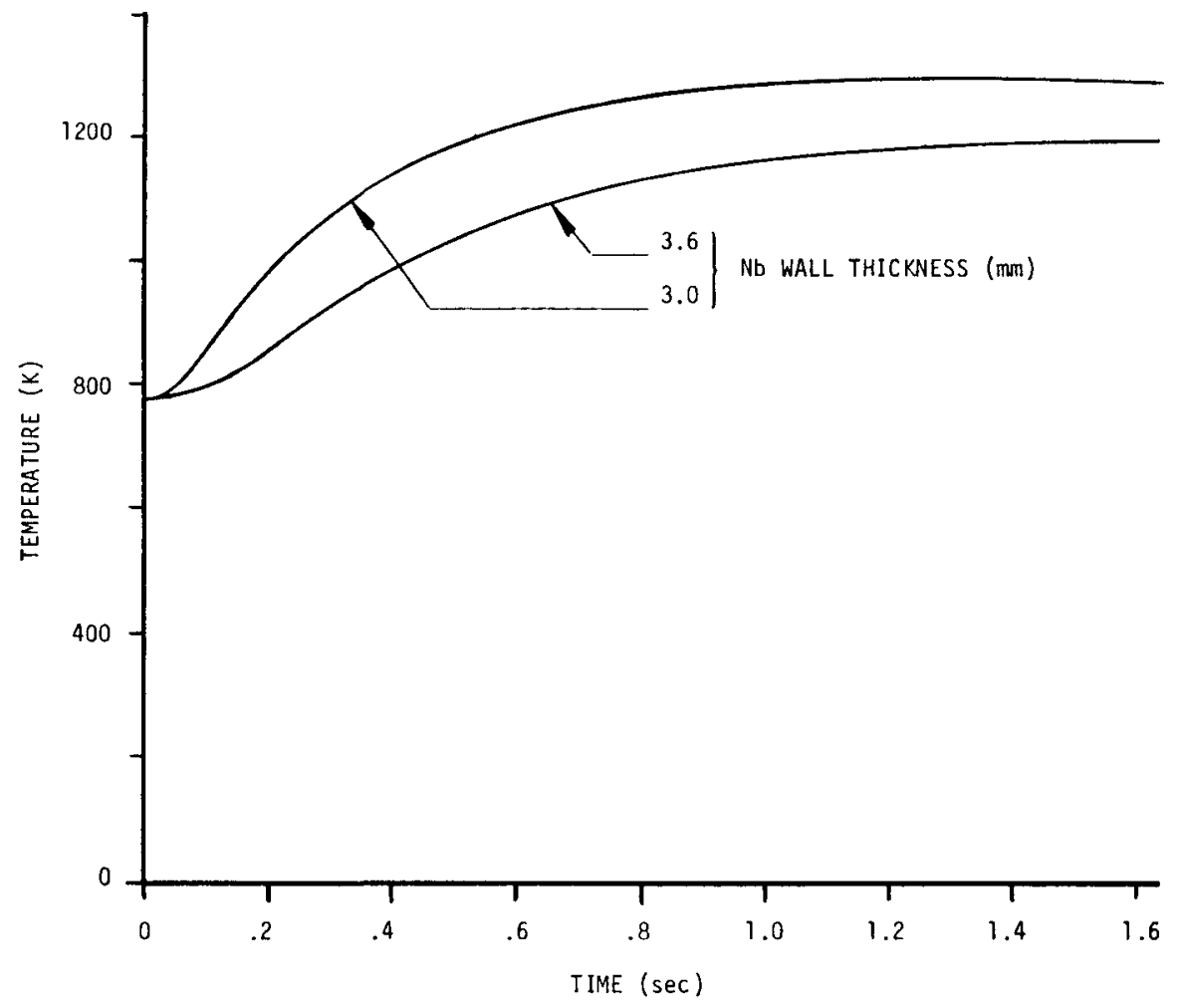

Fig. 5. Maximum sodium bond temperature vs time, as determined by niobium wall thickness. 


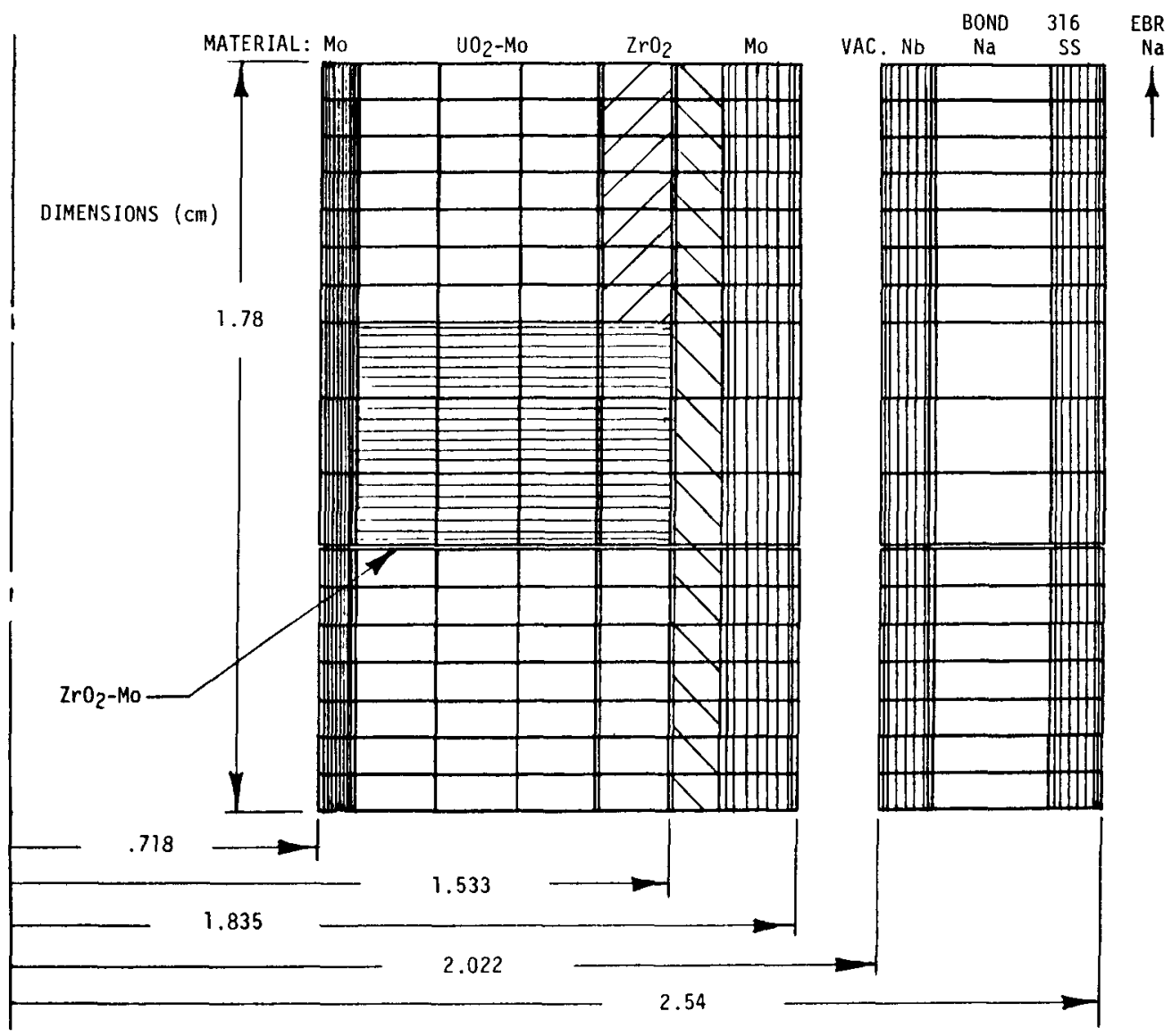

Fig. 6. Axisymmetric model of SPAR fuel container.

This case is for the two test bays having irradiation power densities relative to SPAR of 5.2 and 1.9. Detailed calculation of heat flows showed the radial adiabat is essentially in the $\mathrm{ZrO}_{2}$ insulating sleeve outboard of the fuel--a desirable arrangement because the heat pipe carries off all the $\mathrm{UO}_{2}$ fuel heat and gamma heating of the fuel container is radiated to the niobium capsule wall. Further analysis is required to establish details of behavior with a failed heat pipe.

4. Development. Trial brazing of two molybdenum sleeves to molybdenum heat pipe sections with zirconium wire was successful. Figure 8 shows the samples with accompanying "rolled-out" ultrasonic inspection scans alongside.

A leak-tight zirconium braze of a niobium seal sample to a section of molybdenum heat pipe was made up and temperature cycled six times to $1130^{\circ} \mathrm{C}$ with no subsequent leakage. 

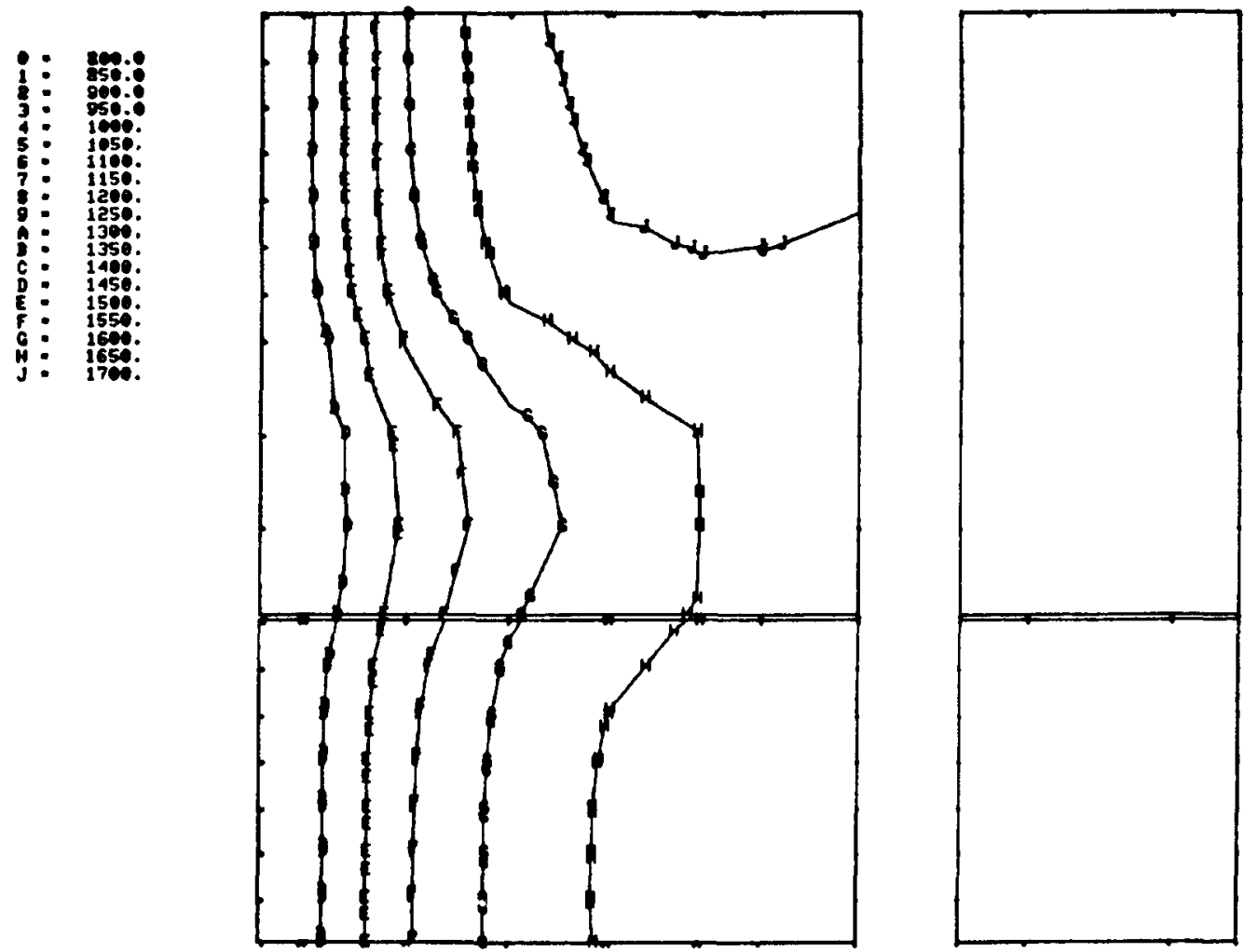

Fig. 7. SPAR fuel container temperature distributions for nominal case.

A survey was started to determine methods of measuring maximum and timeaverage temperatures for the experiment.

5. Fabrication. Fabrication of the $\mathrm{UO}_{2}$ fuel has started. Enough $\mathrm{UO}_{2}$ powder of the required enrichments has been prepared to make the necessary number of fuel washers for the experiment. Isotopic analysis of the powdered $\mathrm{UO}_{2}$ is given in Table I.

Eight specimens, $38.1-\mathrm{mm}$-diam by $1.85-\mathrm{mm}$-thick, were prepared from natural uranium powder (one of the desired enrichments) by cold pressing at $138 \mathrm{MPa}$. Three-weight-percent vinyl acetate was used as a binder. The binder is removed during sintering operations. A 23\% shrinkage occurred during an 8-hr sintering operation at $1800^{\circ} \mathrm{C}$.

Characterization of these specimens is under way. If the material appears satisfactory and the machining tests are successful, the remaining powder will be formed into disks and processed for the EBR-II experiment. 


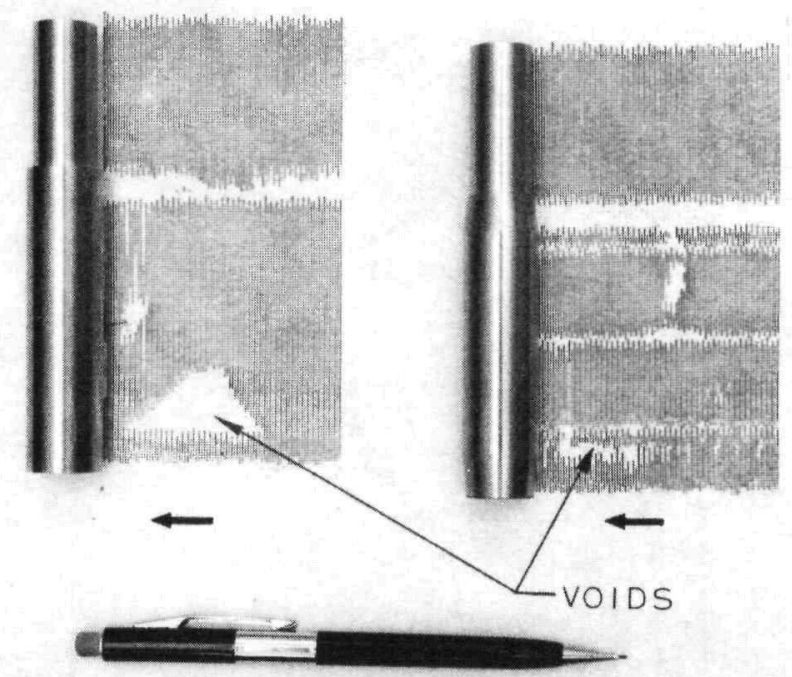

Fig. 8. Trial brazes of molybdenum sleeves, with ultrasonic inspection scans.

\section{TABLE I}

ISOTOPIC ANALYSIS OF UO 2 FUEL FOR EBR-II TESTS

$\mathrm{UO}_{2}$ Sample

Description

Isotopic Uranium Content

\begin{tabular}{|c|c|c|c|c|c|c|c|}
\hline \multicolumn{2}{|c|}{${ }^{234} U$} & \multicolumn{2}{|c|}{${ }^{235} \mathrm{U}$} & \multicolumn{2}{|c|}{${ }^{236} \mathrm{U}$} & \multicolumn{2}{|c|}{${ }^{238} \mathrm{U}$} \\
\hline at. $\%$ & wt\% & at. $\%$ & wt\% & at. $\%$ & wt\% & at. $\%$ & wt\% \\
\hline
\end{tabular}

Natural $\mathrm{UO}_{2}$

0.006

0.006

0.727

0.718

$<0.001<0.001$

99.27

99.28

CMB-8-CUO-907

$26.84 \%{ }^{235} \mathrm{U}$

0.244

0.241

27.31

27.06

0.272

0.270

72.17

72.42

CMB-8-CU0-908

$6 \%{ }^{235} \mathrm{U}$

0.037

0.037

6.22

6.15

0.060

0.060

93.68

93.75

CMB-8-CU0-909 
6. Post-Test Diagnoses. Preliminary discussions of experiment disassembly at Los Alamos National Laboratory were held with hot cell operating personnel. Diagnostic requirements have been set forth. A disassembly procedure was tentatively agreed upon. This will be documented and stored for post-test use as a disassembly plan.

C. Failure Mode and Effects Critical Analysis (FMECA) and Reliability Studies (R. J. Bartholomew, Q-13).

The failure mode state variable models (FMSV) for a core heat pipe thermoelectric converter subsystem have been implemented as (1) a deterministic digital computer code (FAIL2Q), and (2) a Monte Carlo stochastic simulation digital computer code (FL2MCP). Both FAIL2Q and FL2MCP can consider single redundancy of either the heat pipe or the thermoelectric converter. An additional Monte Carlo simulation code, MCP2NR, that considers nonredundancy in the core heat pipe-thermoelectric converter subsystem has also been developed. All of these codes allow for failure mode coupling between the core heat pipe and thermoelectric converter, based on postulated physical processes that may occur between the two different elements. In the FMSV models, certain constraints imposed by the stochastic nature of the Monte Carlo simulation needed to be imposed on the coupling parameters so that the resulting failure mode lifetime probability time histories are correct Markov stochastic model solutions. These constraints were found to be,

1. for the nonredundant model,

$$
\left.\begin{array}{l}
a_{12} \geq 0, \quad a_{21} \geq 0 \\
\lambda_{1}^{*}=\lambda_{1}+a_{12}, \quad \lambda_{2}^{\star}=\lambda_{2}+a_{21} \\
-\lambda_{1} \leq a_{12}-a_{21} \leq \lambda_{2}
\end{array}\right\},
$$

2. for the redundant thermoelectric converter (or heat pipe) model,

$$
\left.\begin{array}{l}
a_{12} \geq 0, \quad a_{21} \geq 0 \\
\lambda_{1}^{*}=\lambda_{1}+a_{12}, \lambda_{2}^{*}=\lambda_{2}+\lambda_{3}+a_{21} \\
-\lambda_{1} \leq a_{12}-a_{21} \leq \lambda_{2}+\lambda_{3} \\
\lambda_{2}=\lambda_{3} .
\end{array}\right\} .
$$


The constraint terms are defined as

$a_{12} \triangleq$ failure mode coupling rate between thermoelectric converter unit and core heat pipe unit affecting core heat pipe lifetime;

$a_{21} \triangleq$ failure mode coupling rate between core heat pipe unit and thermoelectric converter unit affecting thermoelectric converter lifetime;

$\lambda_{1}, \lambda_{1}^{\star} \triangleq$ original (uncoupled) core heat pipe and modified (coupled) core heat pipe failure rates, respectively;

$\lambda_{2}, \lambda_{3} \triangleq$ thermoelectric converter uncoupled failure rates, respectively, $\left(\lambda_{3}\right.$ not considered for nonredundant system); and

$\lambda_{2}^{\star} \triangleq$ modified (coupled) thermoelectric converter unit failure rate.

Further studies with an approximate Monte Carlo simulation model, for conditions where $\left\{a_{12}, a_{21}\right\} c$ an be negative and for $\lambda_{2} \neq \lambda_{3}$ have confirmed that the resulting lifetime probability time histories can still have a probability interpretation; the deterministic solutions are closely approximated by the Monte Carlo simulations, even though we no longer have a Markov stochastic model representation. This important discovery will be the subject of a forthcoming paper on the subject of FMSV models by the author. The result is important to the SPAR program, since now we may reduce the order of the system significantly from that required by a true Markov model, and have the added flexibility of considering interdependent failure mode coupling. The only coupling constraint required is

$\left.\begin{array}{l}{ }^{-\lambda} 1 \leq a_{12}-a_{21} \leq \lambda_{2} \text { for the nonredundant system, } \\ -\lambda_{1} \leq a_{12} 2_{21} \leq \lambda_{2}{ }^{+\lambda_{3}} \text { for the redundant system, }\end{array}\right\}$

together with the requirements $\lambda_{1}^{*}=\lambda_{1}+\mathrm{a}_{12} ; \lambda_{2}^{*}=\lambda_{2}{ }^{+\lambda_{3}}+\mathrm{a}_{21}$.

Using the FMSV digital codes developed, and the SPAR goal failure rates of 3 heat pipes/(90 heat pipes $\times 7$ years) and 1 thermoelectric converter $/(90$ thermoelectric converters $\times 7$ years), which translate to $\lambda_{1}=5 \times 10^{-3} \mathrm{yr}^{-1}$, $\lambda_{2}=\lambda_{3}=1.5 \times 10^{-3} \mathrm{yr}^{-1}$, the effects of coupling $\left\{\mathrm{a}_{12}, \mathrm{a}_{21}\right\}$ were studied. Figure 9 shows the nonredundant failure mode lifetime probabilitv distribution functions for 100 yrs for $F_{1}(t)$ (core heat pipe), $F_{2}(t)$ (thermoelectric converter), and $T(t)$ (top event failure of the subsystem). 


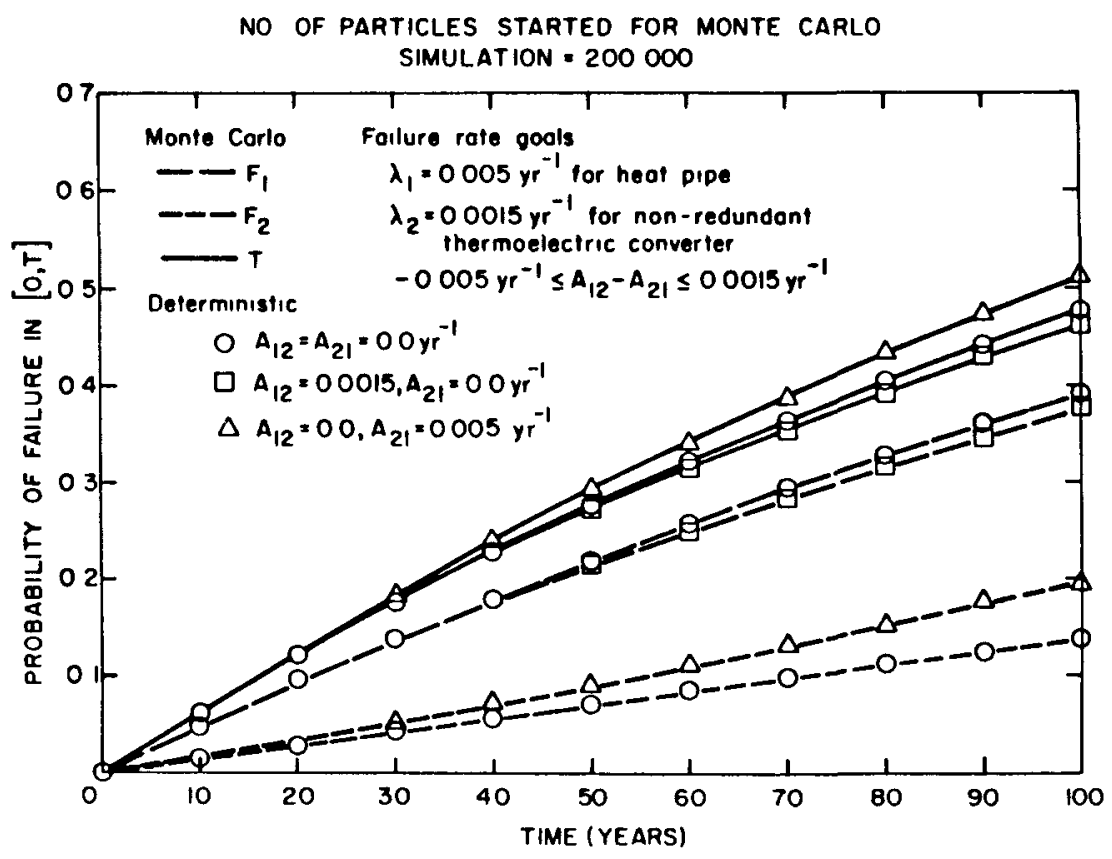

Fig. 9. Expected goal lifetime distribution functions for nonredundant thermoelectric converter and single heat pipe power generation subsystem with failure mode coupling.

Figure 10 shows the effects of single redundancy in the thermoelectric converter, representing a 50\% power loss attributed to the thermoelectric converter. Figure 11 shows the effects of heat pipe redundancy, which would correspond to the effects of two artery wick loops in the core heat pipe, each able to supply 100\% pumping. Figure 12 represents the effects of the relaxed coupling constraints (3) on lifetime distribution of the redundant thermoelectric converter model.

The significant conclusions of these studies are:

(1) The FMSV deterministic models compare well with the Monte Carlo simulations for all cases considered, and the more relaxed constraints on $\left\{a_{12}, a_{21}\right\}$ are allowable;

(2) The effects of allowable intermodal coupling of the failure modes are negligible over a 10-yr lifetime using goal core heat pipe and thermoelectric converter failure rates,

(3) The effects of thermoelectric converter redundancy on expected subsystem reliability are not especially significant, even over a 100-yr period (.51 without redundancy, .45 with redundancy for top event failure probability); and 


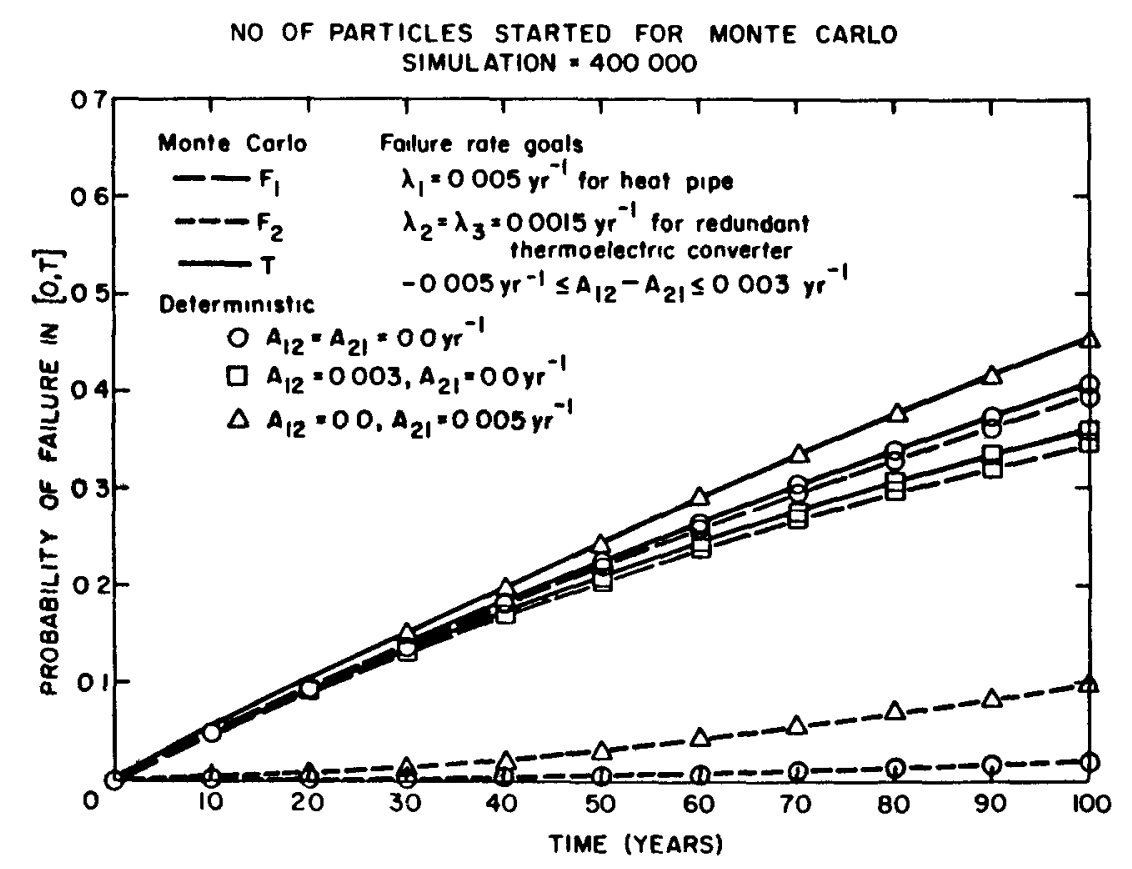

Fig. 10. Expected goal lifetime distribution functions for redundant thermoelectric converter and single heat pipe power generation subsystem with failure mode coupling.

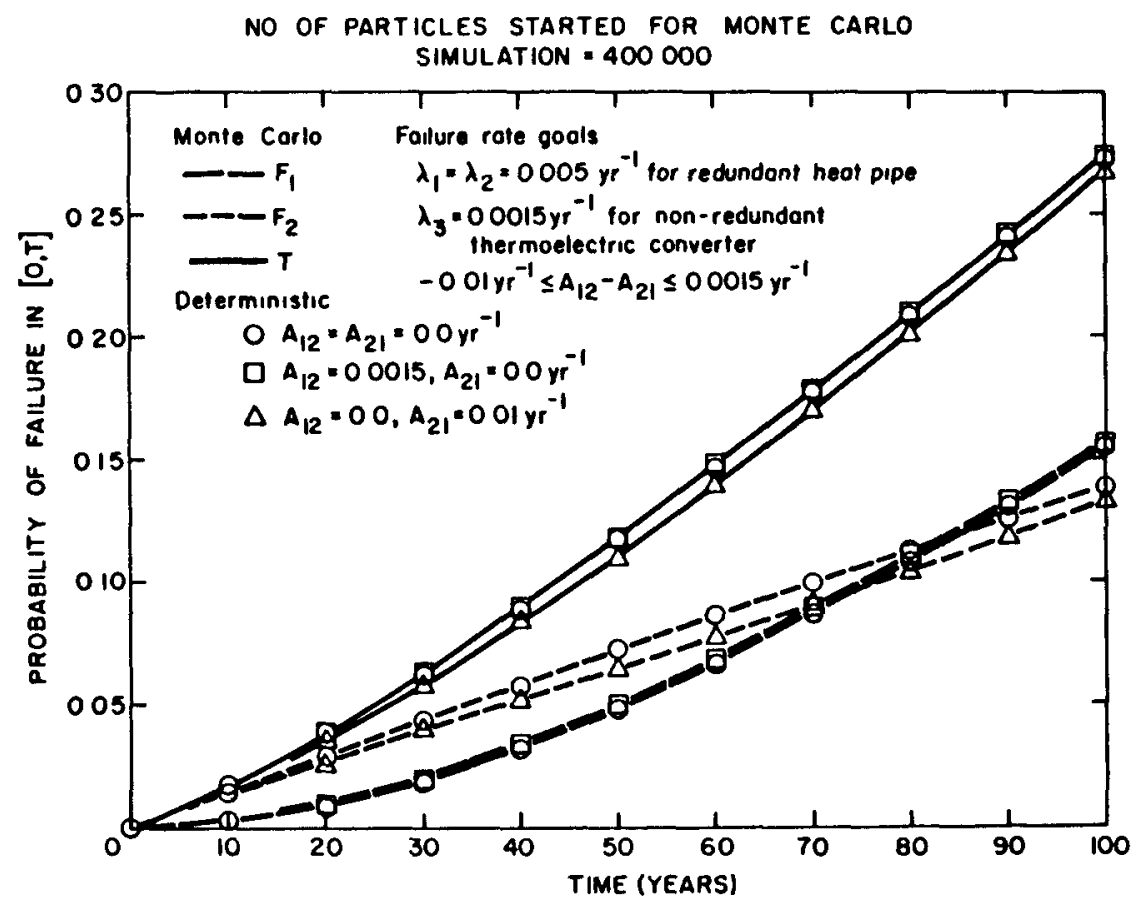

Fig. 11. Expected goal lifetime distribution functions for redundant heat pipe and single thermoelectric converter power generation subsystem with failure mode coupling. 
(4) The effects of heat pipe redundancy are significant over a 100-yr period (.28 with redundancy, .51 without redundancy for top event failure probability).

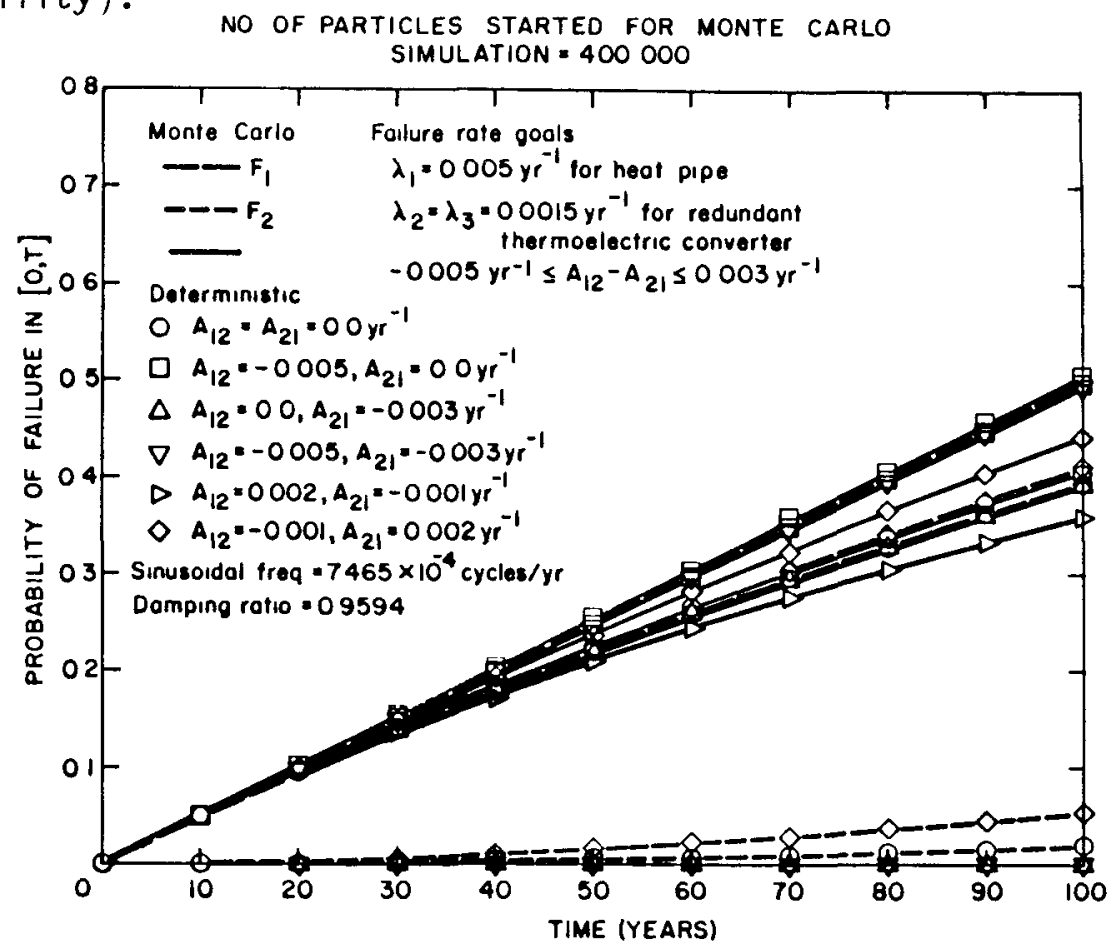

Fig. 12. Expected goal lifetime distribution functions for redundant thermoelectric converter and single heat pipe power generation subsystem with negative and more general failure mode coupling constraints.

IV. CORE HEAT PIPE DEVELOPMENT

A. Heat Pipe Fabrication.

1. SPAR-1B Fabrication and Assembly (H. E. Martinez and E. S. Keddy, Q-13). SPAR-1B is an annular screen tube wick heat pipe with a spirally wound wire between the molybdenum container tube and the screen, which serves to maintain a uniform annular gap. Difficulties in pinching off the molybdenum fill tube of this unit twice resulted in unsuccessful (leaking) assemblies, and led to the development of a closure method that did not rely on flattening the molybdenum tubing. As described in the January-March 1981 quarterly report, this method was successfully used to produce a leak-free unit, which appeared to function properly during initial testing to $1000 \mathrm{~K}$ in the tilt test apparatus used for core heat pipe performance scoping tests. However, 
continued testing in this apparatus later revealed the presence of sufficient noncondensible gas in the heat pipe to prevent operation at tilt angles above a few degrees.

The presence of gas was verified by positioning the heat pipe with the evaporator end down and observing the gas accumulating at the upper end. The position of the gas/sodium vapor interface as a function of heat pipe operating temperature was measured, as shown in Fig. 13, which also shows the positioning of the heat pipe for this test. Gas volume versus temperature exhibited Boyles law dependency, from which it could be determined that this volume was constant at $0.3 \mathrm{~cm}^{3}$ STP over the observed temperature $r$ ange of 865-970 K.

When a hole was drilled in the fill tube of the heat pipe and it was again tested in the position shown in Fig. 13, a residual gas analyzer revealed the presence of $\mathrm{N}_{2}$ and $\mathrm{CO}$ in the combined heat pipe and quartz tube system. After resealing the hole, a further test of the heat pipe showed that

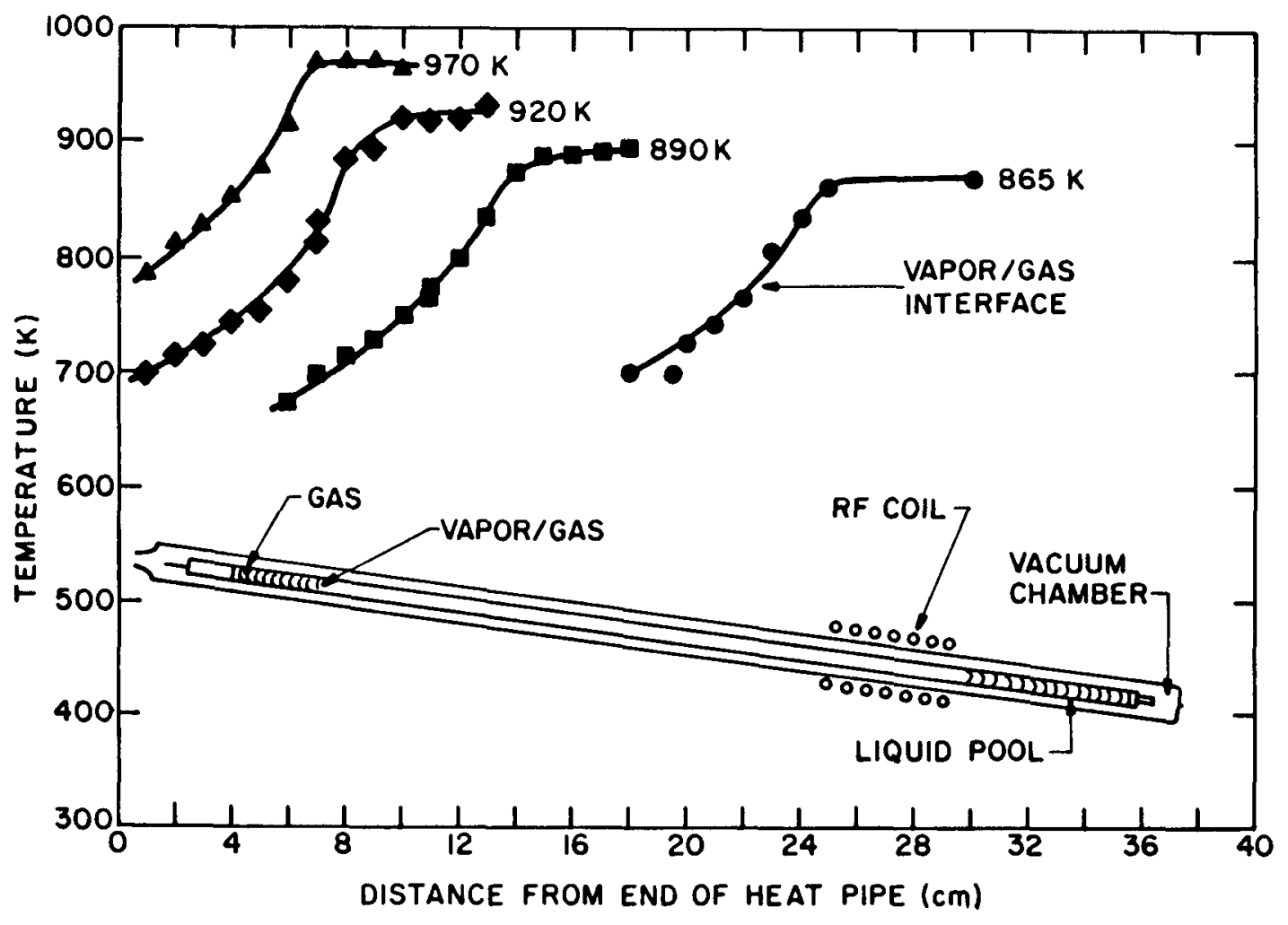

Fig. 13. SPAR-1B heat pipe testing. 
$0.06 \mathrm{~cm}^{3}$ (STP) of the gas was still in the heat pipe. This observation prompted a decision to distill out the sodium working fluid and disassemble the heat pipe.

Examination of the screen tube after disassembly revealed a few very small crystals that were insoluble in alcohol, but dissolved in water. Electron microprobe analysis of two of these crystals showed they contained sodium, oxygen, and carbon, as well as some molybdenum, silicon, and titanium.

When the screen tube was heated in vacuum and off-gasses measured with the residual gas analyzer, it was found that large quantities of $\mathrm{CO}, \mathrm{CO}_{2}$, and $\mathrm{O}_{2}$ were released in the temperature range of 875 to $1125 \mathrm{~K}$. Sodium was also found condensing at the cold ends of the furnace. Raising the screen temperature to $1400 \mathrm{~K}$ yielded little additional outgassing. This finding indicates that sodium carbonate and/or other compounds containing sodium, carbon, and oxygen were present in the wick. The fact that the gas was not evolved until the impurity compounds were heated to $875 \mathrm{~K}$ explains why gas was not detected in the initial tests of this unit. It also explains the difficulty in getting rid of the gas, because more gas was presumably generated when the heat pipe was again heated to high temperature.

One possible explanation of the source of the sodium carbonate-type of compound in this assembly of SPAR-1B is that it formed as a result of air leaking into a previous assembly of this heat pipe (the molybdenum wick could have served as a source of carbon). The screen tube for the present assembly was taken to $825 \mathrm{~K}$ for outgassing, but this was not high enough to remove the impurity compound. This circumstance gave impetus to an effort to build a more versatile heat pipe processing, filling, and testing system.

2. Processing, Filling, and Testing System Construction (H. E. Martinez and E. S. Keddy, Q-13). A new processing, sodium-filling, and testing system has been designed, fabricated, and very successfully employed. The new system is illustrated in Fig. 14. It is basically a quartz tube vacuum chamber with externally mounted rf heating coils. This assembly can be rotated while the heaters are in operation. To begin the processing procedure, the heat pipe is placed in the quartz tube and the system is rotated to a vertical position. The rf coil, which covers the full length of the heat pipe, is activated and the heat pipe assembly is heated to $1400 \mathrm{~K}$ to outgas the heat pipe. After the 


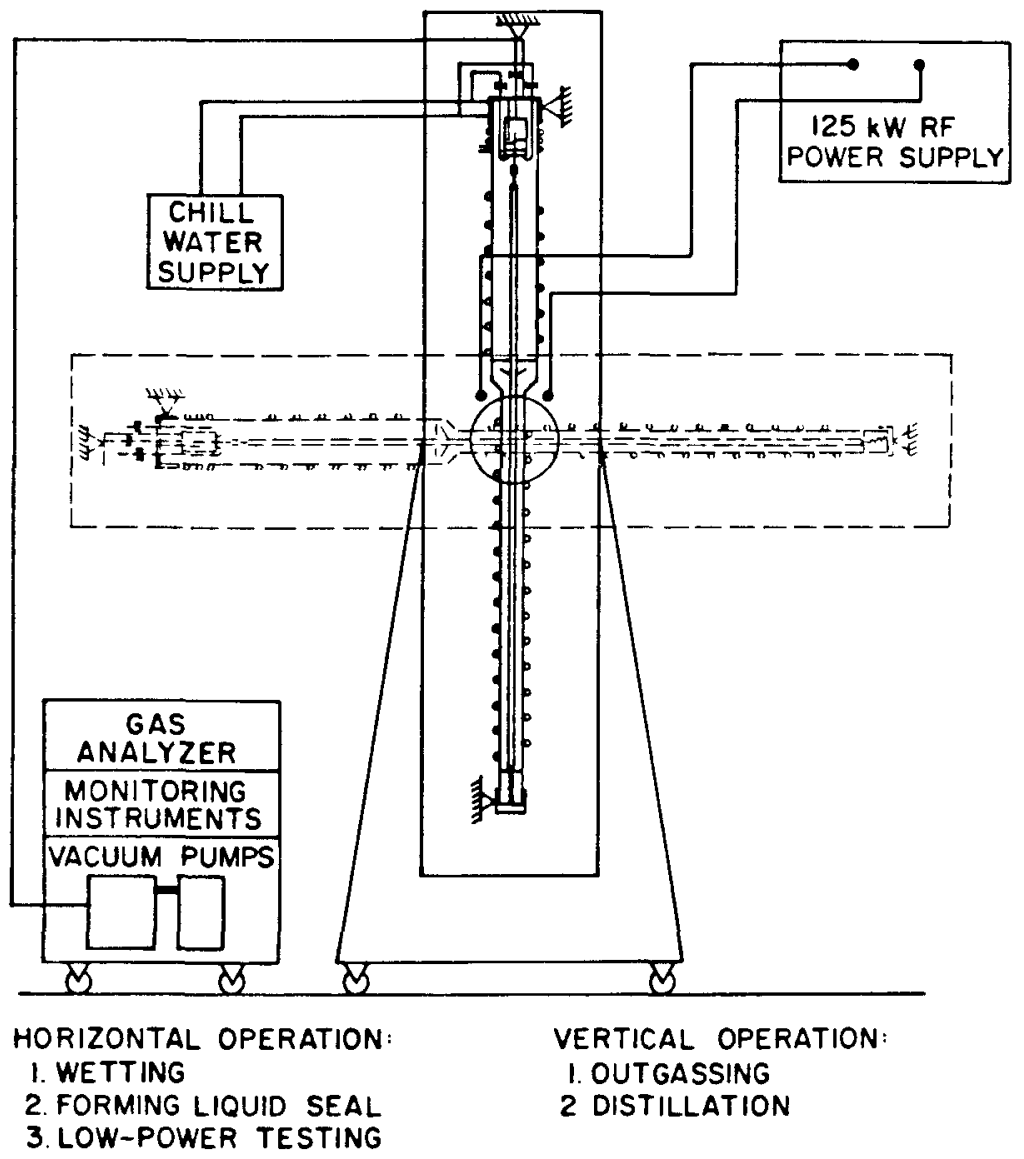

Fig. 14. Heat pipe processing and test system.

heat pipe has been outgassed, an $r f$ heating coil at the distillation pot, Fig. 15, is connected in series with the heat pipe coil and the sodium in the distillation pot is slowly outgassed. During the sodium outgassing, the fulllength rf coil supplies heat to the heat pipe, keeping it above the melting point of sodium. After the sodium is outgassed, the distillation pot is heated to approximately $850 \mathrm{~K}$ and sodium is distilled into the heat pipe. A thermocouple in the well of the distillation pot is used to determine when distillation is complete. The heat pipe and distillation pot are allowed to $\mathrm{cool}$, and the system is then rotated and set up horizontally. The rf coil from the distillation pot is disconnected, and the chill is activated by flowing water around the 6.35-mm-diam stainless steel tubing connecting the distillation pot and the heat pipe.

The full-length $r f$ coil is activated and the heat pipe heated, distributing the sodium in the heat pipe and wetting the molybdenum. At the same time, sodium vapor flows into the 6.35 -mm-diam fill tube and condenses and solidifies 


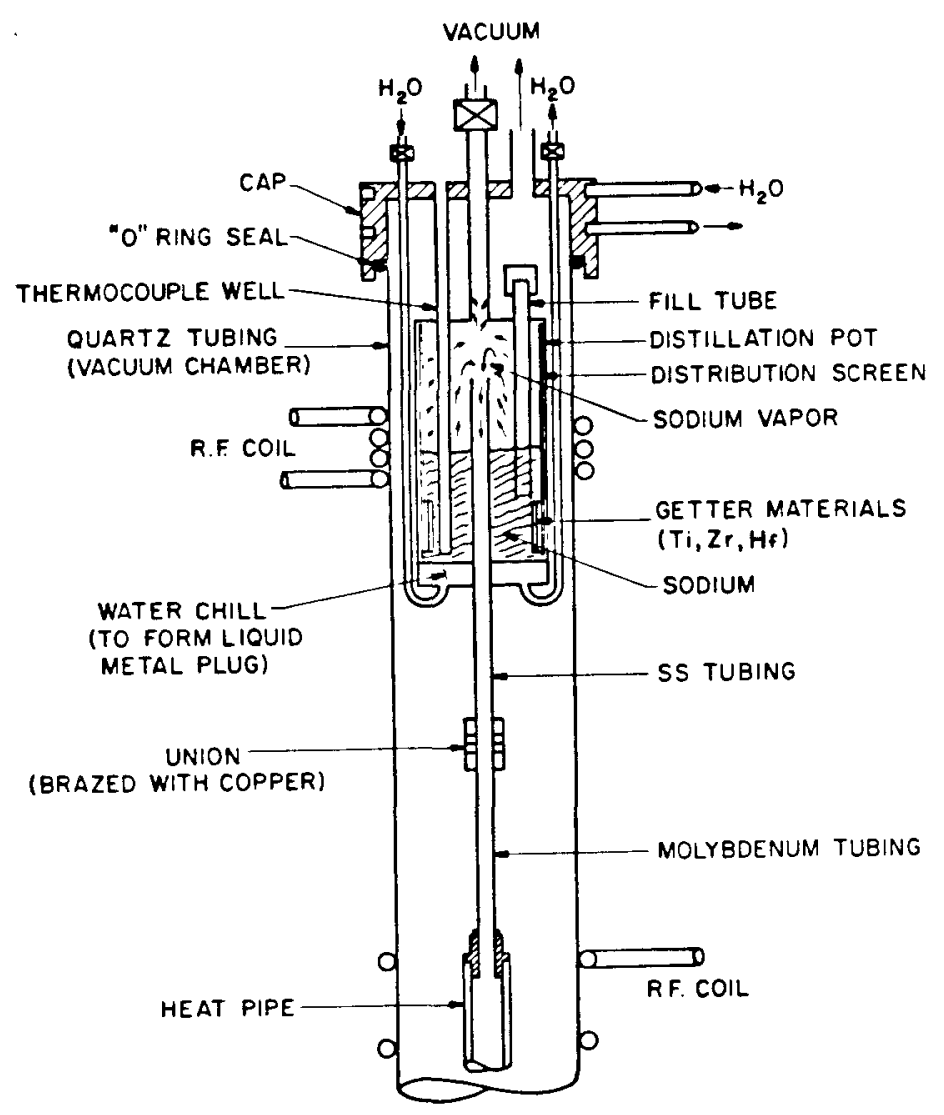

Fig. 15. Distillation apparatus.

at the chill, forming a solid sodium plug. After wetting of the heat pipe is complete, an rf coil at the evaporator end of the heat pipe is connected and the heat pipe is tested at low power. Heat is removed through radiation losses only. The heat pipe is tilted to work against gravity and the pipe's capillary pumping ability is evaluated. The heat pipe is also evaluated for the presence of gas or excessive sodium fill. Either gas or excess sodium can be removed with the system if required.

The heat pipe and distillation pot assembly are then removed from the quartz vacuum chamber; the heat pipe is removed from the pot by disconnecting the Swagelok joint nearest the distillation while under a cover of argon gas. The fill-tube end of the heat pipe is radiographed to verify the presence of a solid plug of sodium in the fill tube. This plug will preserve the vacuum with in the heat pipe. The heat pipe is enclosed in an argon-filled bag, and the molybdenum fill tube is cut off with a small hand saw; a support block 
aids in holding the tube and guiding the saw. A molybdenum cover is placed over the fill tube in preparation for welding. The heat pipe is then transported to the electron beam (EB) welder in the argon-filled bag, minimizing exposure of the sodium to air. The heat pipe is assembled into the EB welder box, evacuated, and pumped for several hours to ensure the removal of all the argon gas within the cover over the fill tube.

After EB welding, the heat pipe is reassembled into the process's tilt system and operated at design temperature, examining for sodium leaks in the welds and rechecking the performance of the heat pipe.

This system has been used to process and refill SPAR-1B and also to fill SPAR-4, the first molybdenum/sodium artery heat pipe. Both assemblies were free of gas, and neither required the removal of excess sodium. Figure 16 shows SPAR-1B operating at a $58^{\circ} \mathrm{tilt}$, with the evaporator end up, at approximately $1200 \mathrm{~K}$.

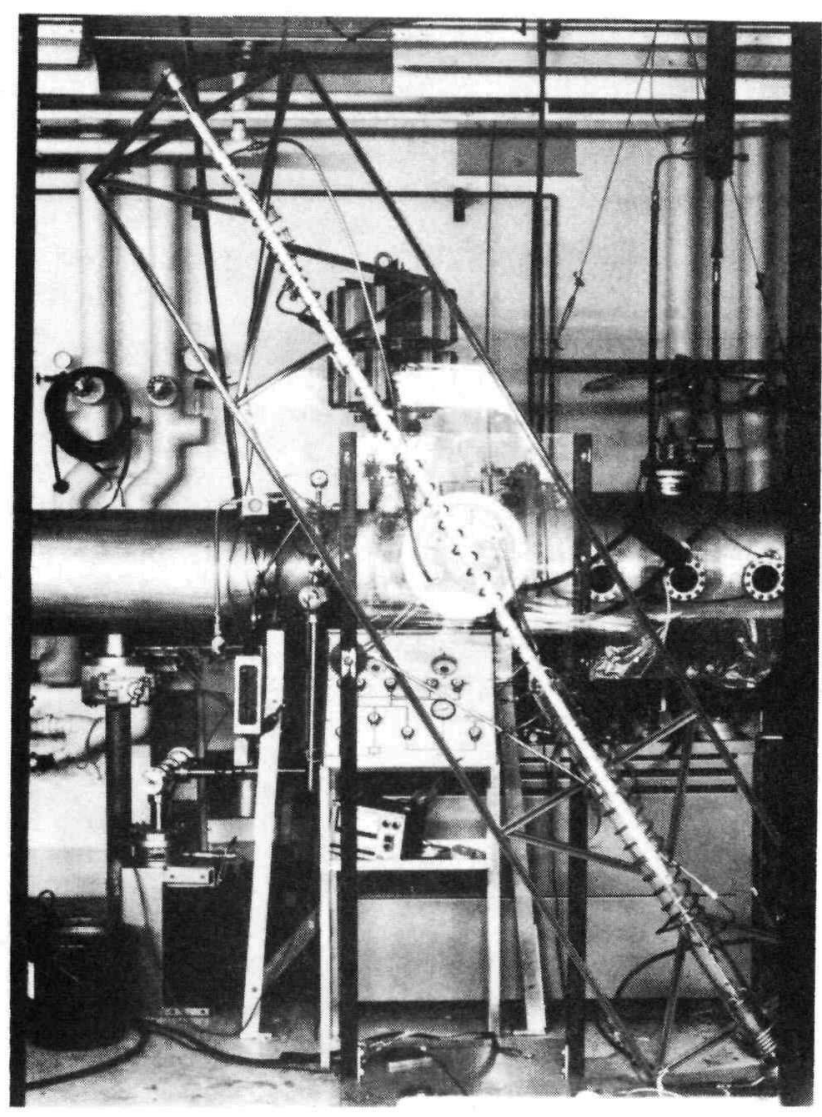

Fig. 16. SPAR-1B tilt test. 
3. SPAR-4 Fabrication (J. Runyan, Q-13). SPAR-4 is the first molybdenum/ sodium heat pipe with an arterial wick configuration. It has two arteries, placed $180^{\circ}$ apart, which are attached to a distribution wick by spot welding. The distribution wick lines the inner wall of the molybdenum tubing used to fabricate the pipe. It is made of six layers of 150 mesh molybdenum screen compressed between concentric tubes of Shelby steel.

A large number of steps are required in the fabrication, assembly, and processing of an artery heat pipe. These are listed in Fig. 17, along with the times required for completion.

Several of the fabrication and assembly tasks required considerable preliminary development and analytical work before they could be performed. An example is the drawing down of the molybdenum tubing on the tubular distribution wick. A number of relatively short samples of tubing and wick were drawn down in order to arrive at optimum contact between the two; close contact is desirable to avoid the development of pockets of liquid that might be subject to a boiling limit. The tests showed that too much reduction of the container tube produced a longitudinal fold in the distribution wick. The die size adopted for drawing down the 2-m tube to form SPAR-4 avoided this effect, but it resulted in a gap of about $100 \mu \mathrm{m}$ between the distribution wick and the wall.

Because the arteries are spot welded to the distribution wick at 8-mm intervals, as shown in Fig. 18, there is a potential for separation of artery and distribution wick to occur between spot welds. Radiographic examination of the SPAR-4 assembly showed no gaps of more than about $25 \mu \mathrm{m}$, which should not interfere with the flow from artery to distribution wick.

The several trial draws of short sections of molybdenum tubing on a section of distribution wick all went smoothly, but a problem developed when the $2-m$ pipe was drawn. As the drawn length approached $30 \mathrm{~cm}$, the smooth travel was interrupted by a stick/slip motion. The draw rate of $10 \mathrm{~cm}$-per-minute (4-in.-minute) was varied and additional lubricant was applied. No external damage was apparent so the $d r a w$ was completed despite the intermittent recurrence of the stick/slip motion. Jarring from the stick/slip problem may have been severe enough to have caused damage to the heat pipe, particularly to the welds holding the arteries to the wick. Correction of the problem may be realized by replacing the Dillon "C" frame force gage with a load cell. The 


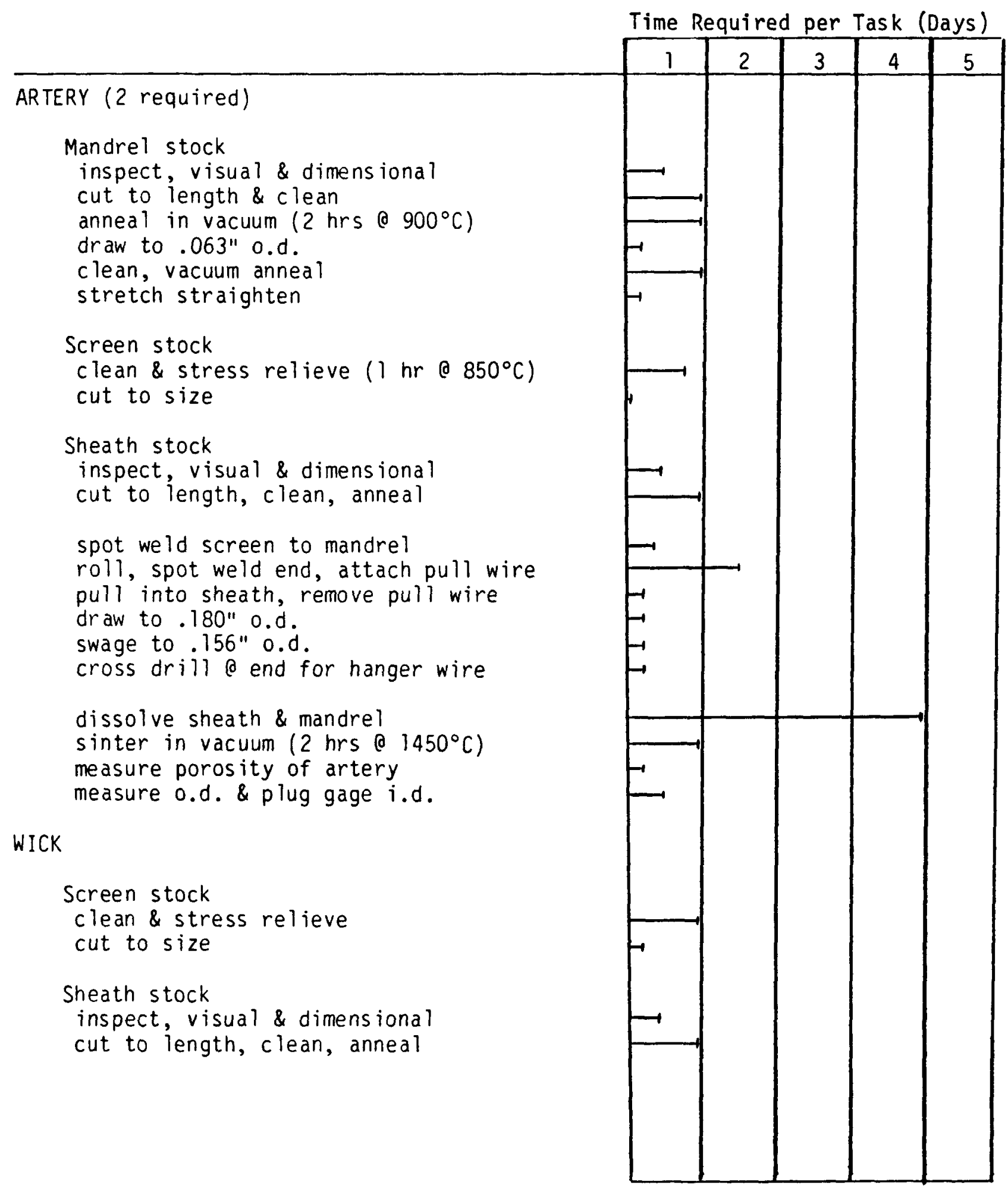


Artery Heat Pipe Fabrication Tasks (Cont'd)

Time Required per Task (Days)

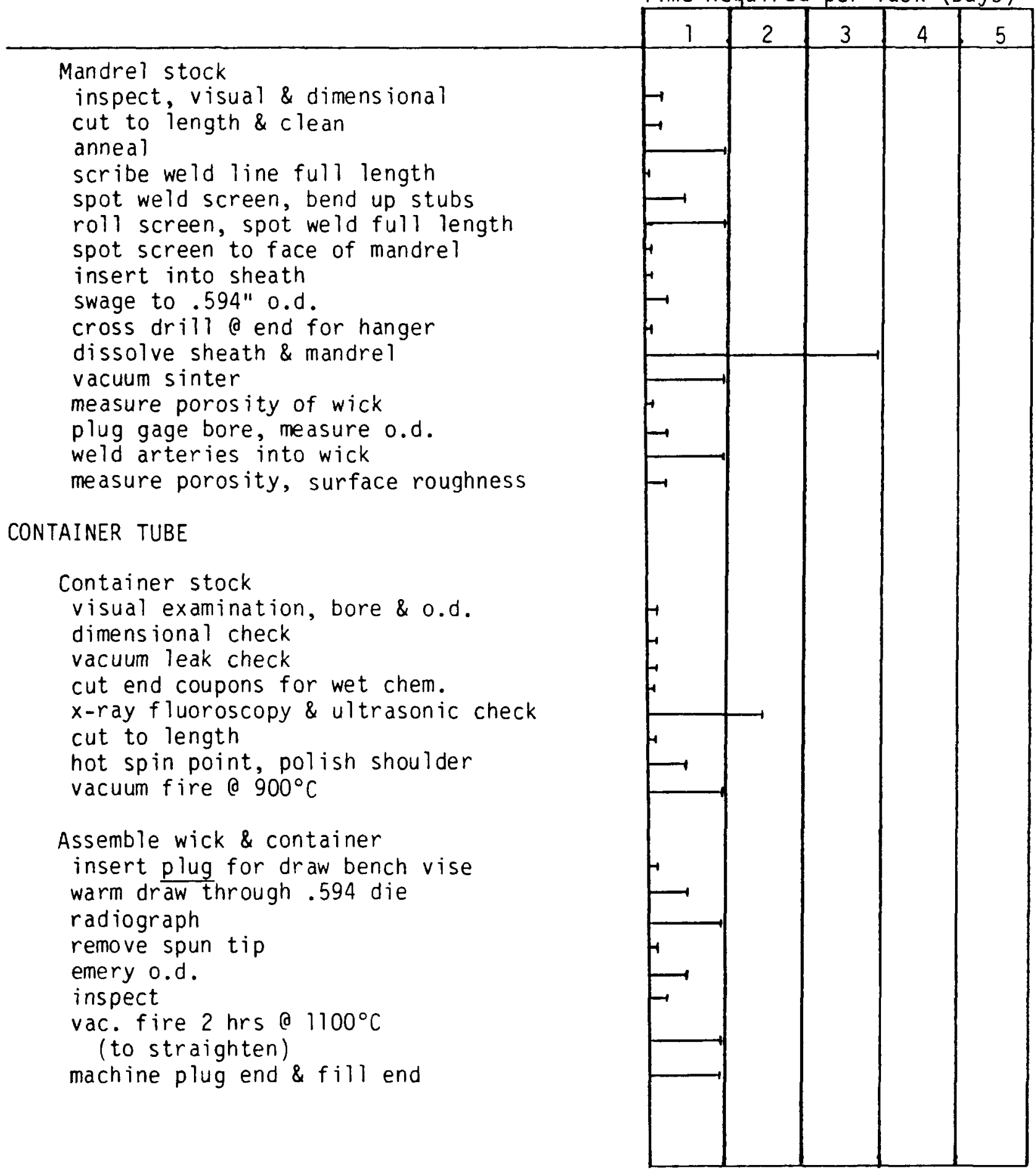




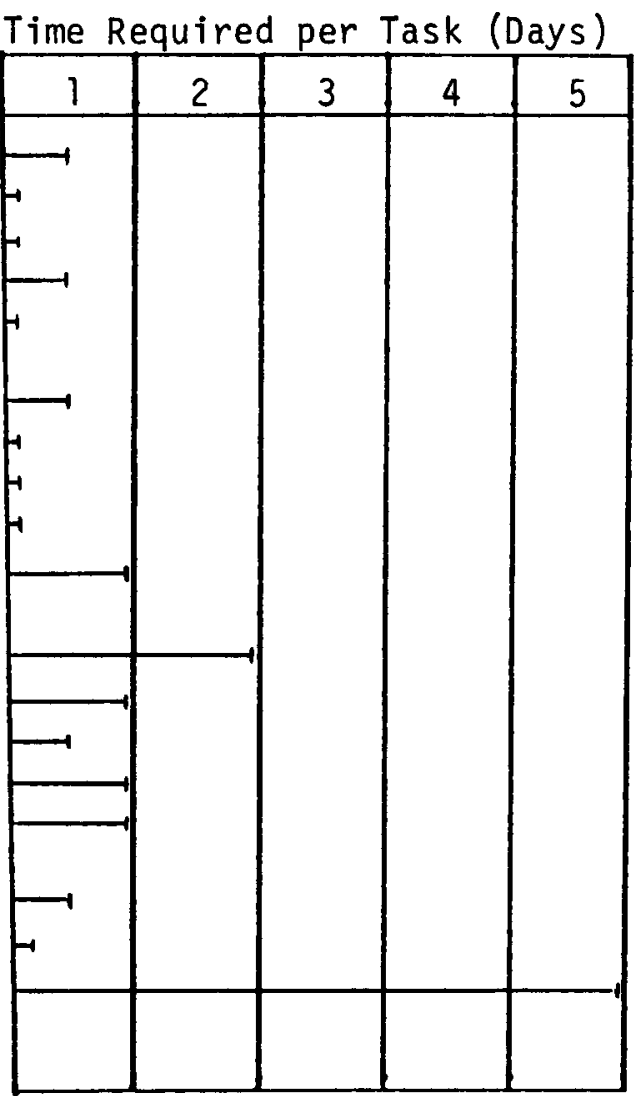

Fig. 17. Artery heat pipe fabrication tasks.

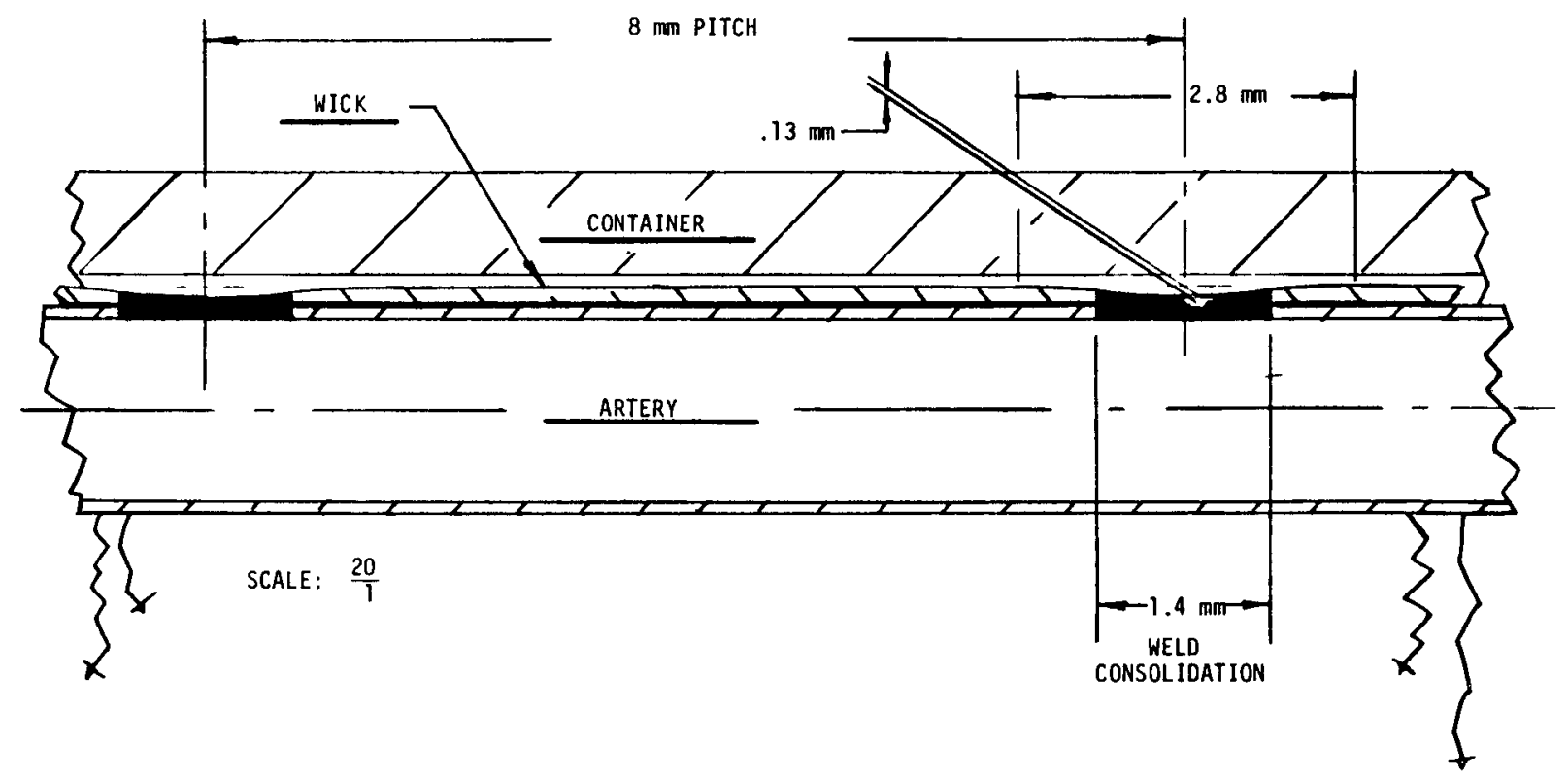

Fig. 18. SPAR-4 typical weld of wick to artery. 
load cell should be considerably less flexible and provide a more stable loading characteristic.

The getter for SPAR-4 consists of 12.7-mm-diam (.05-in.) disks of hafnium and zirconium stacked alternately. These were contained at the evaporator end of the heat pipe in a short chamber, bounded by the end plug and a screen cup that was welded into the end of the wick.

Small effective pore size in the cup promotes wicking of liquid into the getter chamber, allows evaporation from its surface into the evaporator, and prevents intrusion of vapor into the getter chamber. Diffusion gradients in this chamber should transfer trace amounts of oxygen contained in the sodium in the evaporator to getter surfaces.

Figure 19 is a $7 X$ center-line section of the finished cup, which was formed with the tools shown in Fig. 20. The black circles and stringers in the cup are holes in the potting compound. Ten square swatches of 150 mesh

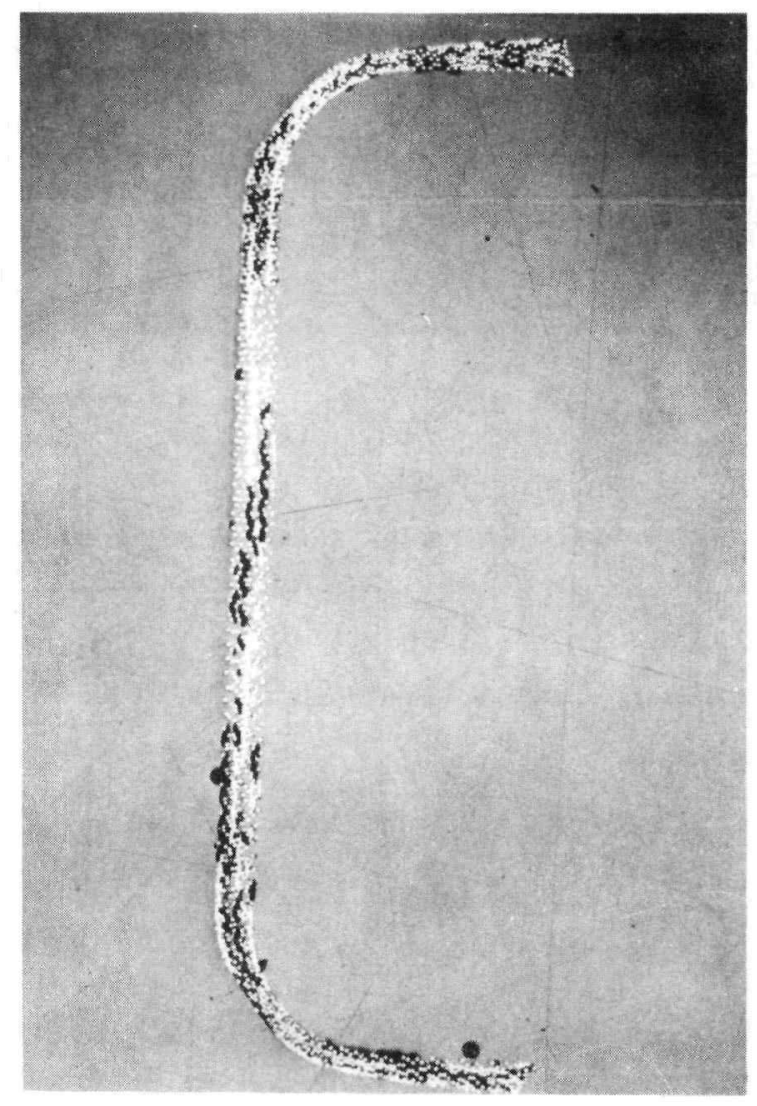

Fig. 19. $7 X$ cross section of screen cup. 
molybdenum screen were compressed between the ends of the two steel mandrels shown in Fig. 20. The assembly was then spun in a lathe, using the wall of the steel cup as a backing to cushion the underlying screen from tearing forces it would otherwise suffer from the wiping action of the spinning tool.

Pore tests of the arteries after assembly to the distribution wick showed maximum openings on the order of $90 \mu \mathrm{m}$. This was the dimension anticipated when it was decided to build an artery heat pipe with available 150 mesh screen, rather than wait until finer mesh molybdenum screen could be produced.

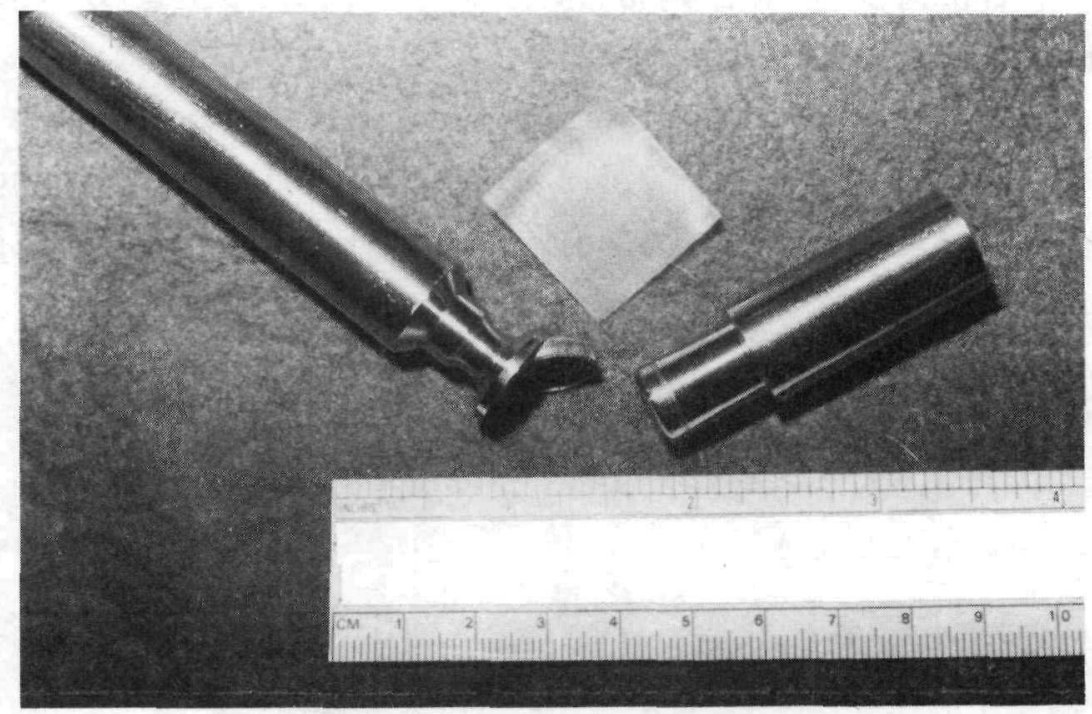

Fig. 20. Screen cup, mandrels, and swatch of molybdenum screen.

4. Production of Fine Molybdenum Screen (L. B. Lundberg, Q-13). Low carbon arc cast ( $L C A C$ ) molybdenum wire is being woven into $355 \times 388$ mesh screen by Dürener Metalltuch in West Germany. We had hoped to obtain $400 x$ 400 mesh screen, but apparently the wire was not ductile enough to produce this finer weave. When received, this screen will be used to develop production methods for artery wicks.

Mo-41 wt\% Re alloy wire is presently being drawn to 25-um diam so that we might produce a $400 \times 400$ mesh artery wick ductile enough to bend at room temperature or below. Mo-13 Re alloy is also being prepared. This alloy will be drawn into 25-um-diam wire for eventual weaving into fine mesh screen. 


\section{B. Core Heat Pipe Test and Analysis (F. C. Prenger, Q-13).}

The SPAR-4 core heat pipe with artery wicking was tested at varying tilt angles, to a temperature of $1373 \mathrm{~K}$, in the inductively heated quartz tube furnace. Results of this test have been analyzed to determine the performance characteristics of the artery design. The tilt test is designed to simulate a load on the heat pipe by forcing it to pump against a gravity head. This is accomplished by elevating the evaporator above the condenser. Since the gravity head is a function of the heat pipe tilt angle, the load can easily be varied. Heat is added by induction and rejected from the bare heat pipe by radiation. The emissivity of the molybdenum heat pipe was assumed to be 0.15 .

Because one of the dual arteries of SPAR-4 became separated from the evaporator distribution wick during final assembly, this unit provided an opportunity to study the effects of both one- and two-artery performance in the same heat pipe. This was done by first taking data with heat introduced in the normal evaporator region, where only one artery was attached, and then moving the heat source down the pipe to a region where both arteries were attached and contributed to the heat pipe operation.

Heat transfer limits measured for SPAR-4 as a function of tilt angle for one-artery operation are shown in Fig. 21. The analytical curve that fits this data is based on 80-um pore size, one-artery performance, and flow resistance in the distribution wick that is 10 times that for an ideal homogeneous, screened wick. The 80 -um pore size gives a pumping power for the artery of about $40 \%$ of the baseline design. It is the value expected when the decision was made to proceed with the fabrication of SPAR-4 using off-the-shelf 150 mesh molybdenum screen, instead of the 360-400 mesh that will soon be available.

The distribution wick flow resistance is indicated by the SPAR-4 one-artery performance data to be relatively high. It consists of the impedance the liquid in the artery encounters in flowing from the artery to the distribution wick and also in flowing circumferentially in the distribution wick. Ordinarily this impedance is low because the liquid flow path is short. However, if the arteries are not attached uniformly to the distribution wick, a much larger flow path can result, with a corresponding increase in liquid pressure drop. In the SPAR-4 heat pipe the arteries were attached to the distribution wick by spot welds on 8-mm centers. Radiographic analysis has shown irregular contact between the arteries and distribution wick, especially in the area 


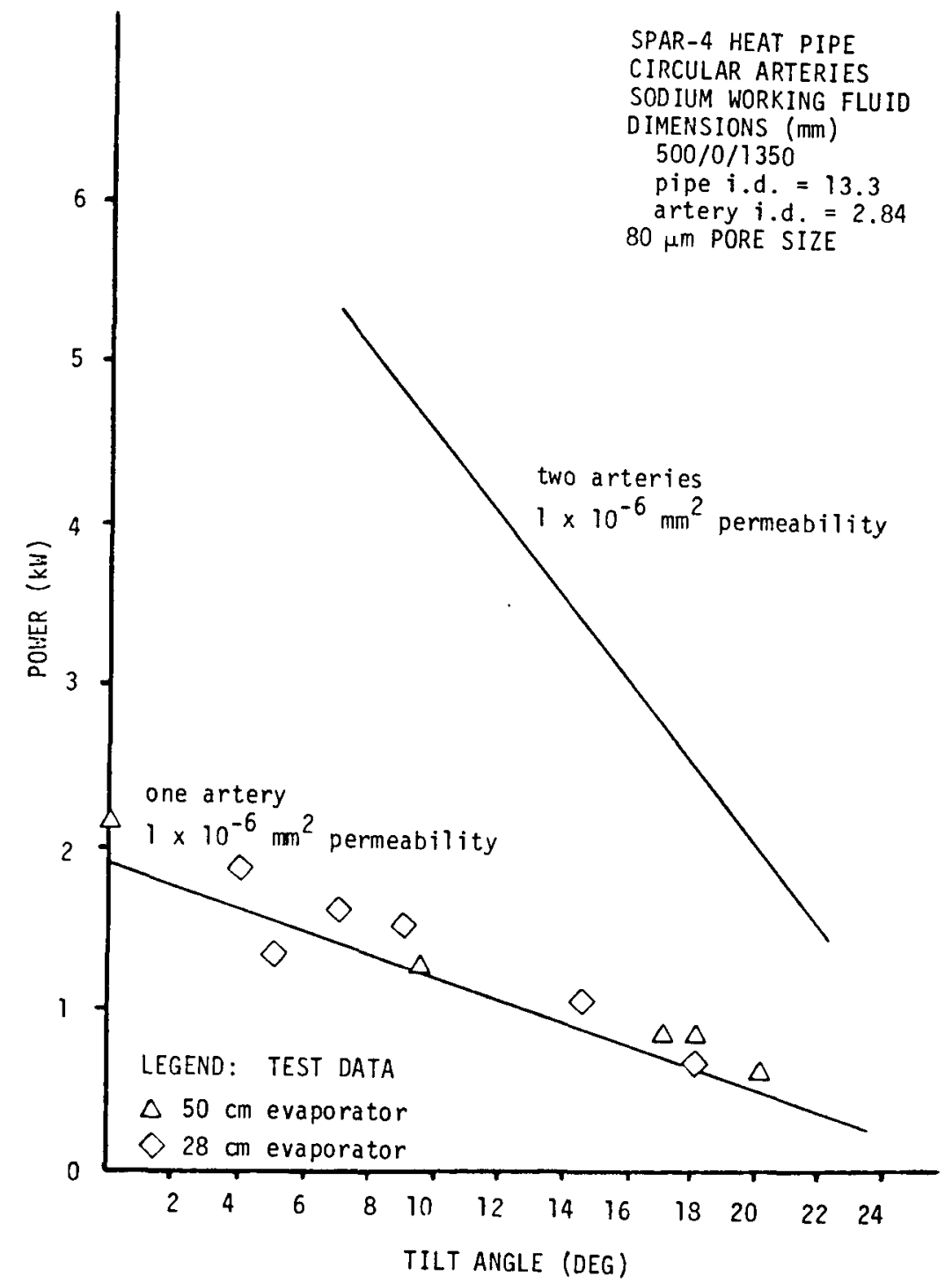

Fig. 21. Measured and calculated heat transfer of SPAR-4 as a function of tilt angle.

between welds. However, the gap between artery and distribution wick must be larger than $80 \mu \mathrm{m}\left(0.003^{\prime \prime}\right)$ to interrupt the liquid flow to the distribution wick. This was nowhere the case for the artery that was well attached to the distribution wick. Another possible source of high impedance is excessive tortuosity in the distribution wick itself. This explanation is difficult to justify because of the low impedance expected for the $0.1-\mathrm{mm}$ gap that was observed between the distribution wick and heat pipe wall, as noted above. Nevertheless, the data are best fit by an assumed permeability of $1 \times 10^{-12} \mathrm{~m}^{2}$, or $10 \%$ of the ideal case. 
Also shown in Fig. 21 is the heat pipe performance with both arteries operating. The increase in heat transport capability is due primarily to the reduced flow path in the distribution wick resulting from two arteries. Preliminary test data, obtained by heating the heat pipe just below the region where one artery is detached from the distribution wick, indicates agreement with the calculated performance, exceeding $3 \mathrm{~kW}$ at a test angle of $12^{\circ}$.

Effects of boiling and thermophysical property variation due to contamination were also investigated; however, these effects produce performance characteristics different from those observed in the tests. Continued testing of the SPAR-4 unit is in progress, with an aim towards determining the cause of the apparently excessive liquid pressure drop so that suitable corrective action may be taken, such as introducing more arteries, reducing the impedance where the arteries attach to the distribution wick, or reducing flow impedance in the distribution wick itself.

C. Alternative Artery Wick Fabrication Methods.

1. CVD Artery Wick Fabrication (K. L. Meier, Q-13, and W. McCreary, CMB-6). Chemical vapor deposition (CVD) experiments are being conducted to attempt to uniformly reduce the porosity of heat pipe wicks by the CVD of molybdenum and tungsten. Success in this endeavor would allow the use of readily available 150 mesh screen for arteries and distribution wicks, with a subsequent pore size reduction from $130 \mu \mathrm{m}$ to $35 \mu \mathrm{m}$ by CVD.

Initial CVD experiments attempted to coat molybdenum uniformly on molybdenum screen tubes using the reacting gases $\mathrm{MoF}_{6}$ and $\mathrm{H}_{2}$. Coatings were nonuniform, both circumferentially and axially over 50-mm lengths. In addition, the hoped-for bonding between screen layers and of arteries to distribution wick did not materialize.

The vertical, top-end gas-feed, rf-coil-heated apparatus used in the initial experiments was modified to provide a greater entrance length, and flow straighteners were added to produce a more uniform gas flow over the sample. These improvements were not sufficient to produce a uniform molybdenum coating, although the uniformity of tungsten coatings was somewhat better.

In an attempt to improve the CVD coatings, a 300-mm-long, horizontal, electrically heated, CVD apparatus was designed and fabricated. It has a 
drive motor to rotate the sample, and uses long perforated tubes to feed in the reacting gasses over the entire length. Molybdenum coating with this apparatus was slightly improved, but uniform coating was still not obtained. However, coating with tungsten proved to be a highly successful operation. The first tungsten coating experiment in the horizontal apparatus consisted of CVD-coating a single wrap, 13-mm-diam, 100 mesh molybdenum screen tube $120 \mathrm{~mm}$ long. The results are shown in Fig. 22. This photograph is a representative sample of an excellent coating that was uniform circumferentially and varied only $10 \%$ over a $120-\mathrm{mm}$ length. The size of the holes was originally $190 \mu \mathrm{m}$, and was reduced to $110 \mu \mathrm{m}$ by tungsten CVD. The next test will use a 300-mm-long, 150 mesh screen which, when coated over a slightly longer period, should produce a $35-\mu \mathrm{m}$ pore size.

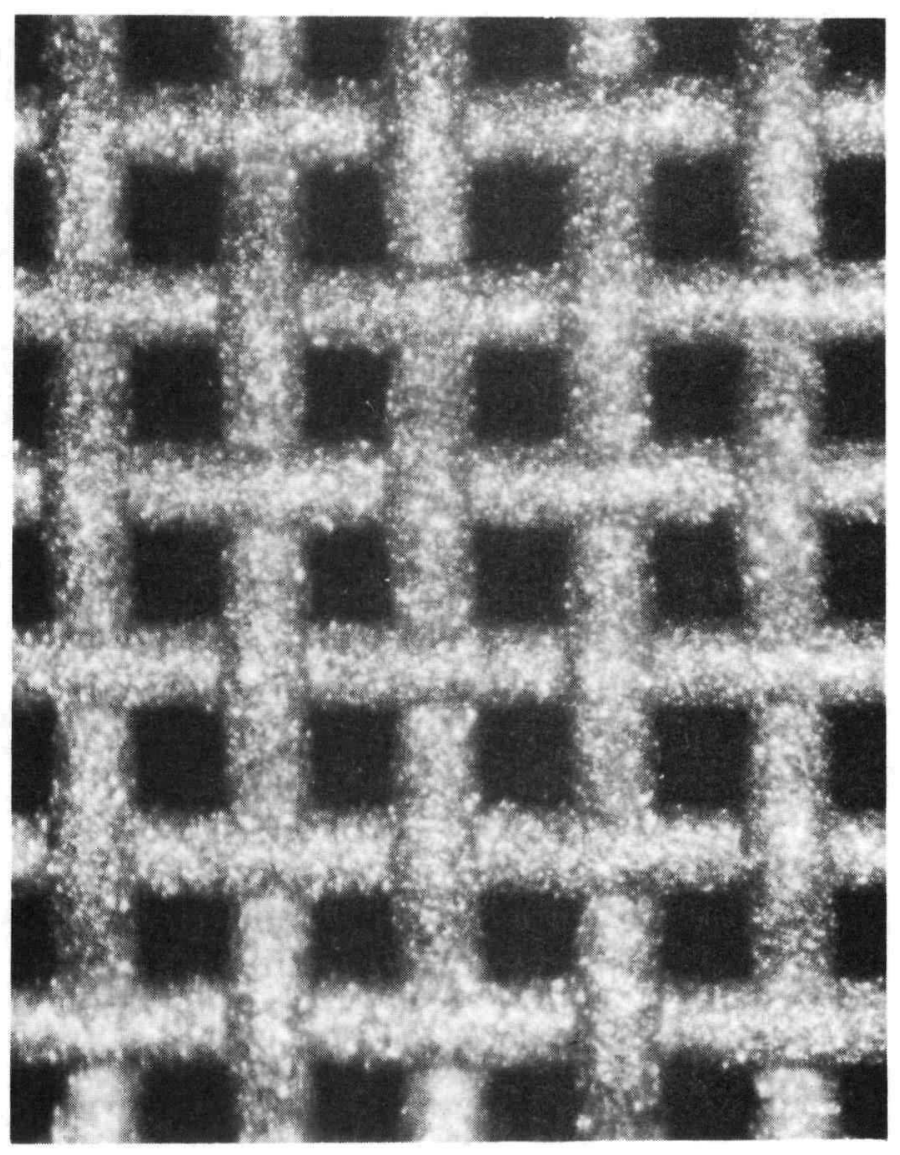

Fig. 22. Uniform CVD coating of 100 mesh molybdenum screen $(70 \mathrm{X})$. 
2. Porous Metal Artery Wicks (L. B. Lundberg, Q-13, C. Wojcik, Teledyne Wah Chang Albany). Teledyne Wah Chang Albany (TWCA) has been working on a process for producing a niobium porous metal artery wick that is metallurgically bonded to the inside of a molybdenum tube. A sample assembly about $10 \mathrm{~cm}$ long has been made, and it has been shipped to us for evaluation. Of special interest is the porosity of the wick and the quality of the bond between the two metals.

The porous niobium layer has some variations in wall thickness, but this could be corrected with more precise tooling. As can be seen in Fig. 23, the arteries have a square external cross section. This was done to simplify the construction of this developmental assembly, and it is anticipated that no difficulties will be encountered in producing an artery with a circular exterior. We also feel optimistic about producing longer lengths of wick.

3. Felted Metal Wicking Structures (J. V. Milewski, CMB-6). Another approach to making an artery wick for molybdenum heat pipes involves felting fibers of molybdenum or niobium into the desired shape and sintering the felt

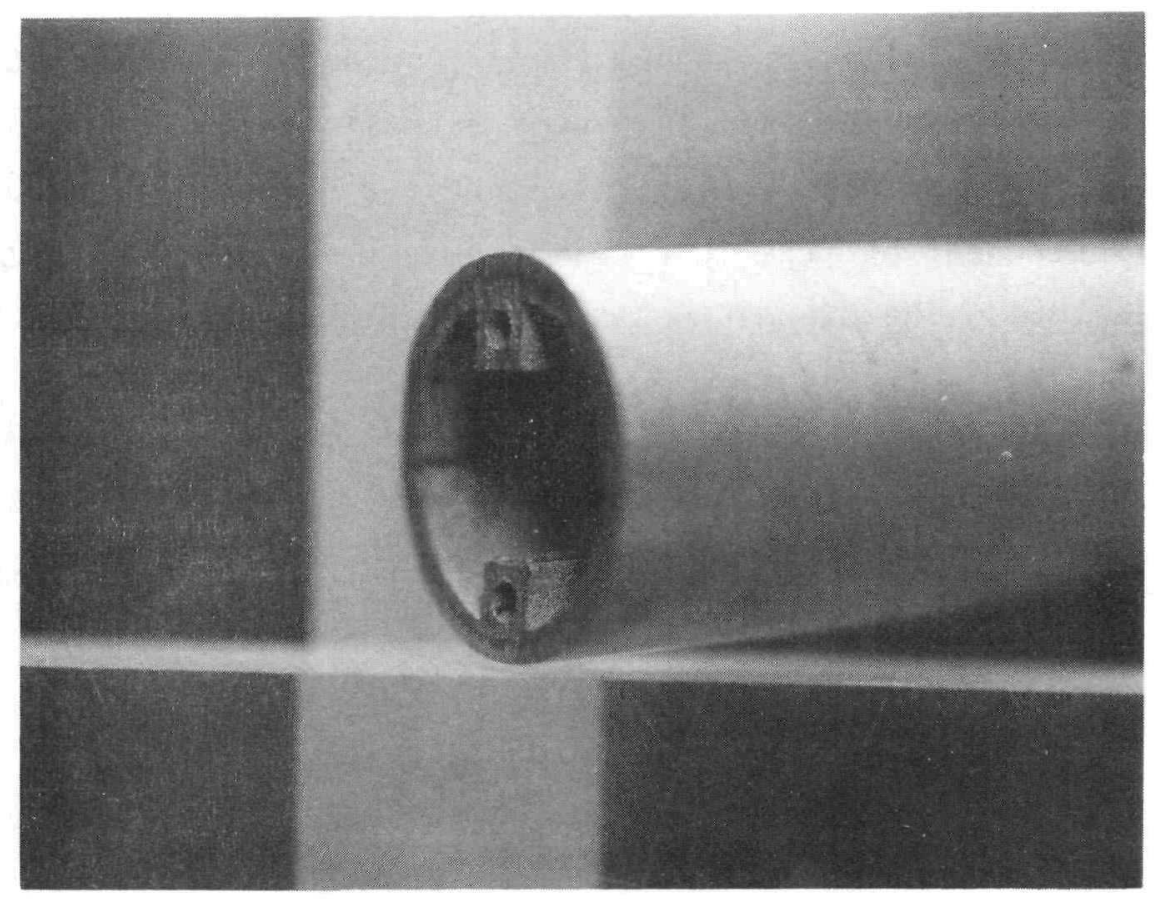

Fig. 23. Niobium porous metal artery wick inside 15.9-mm-o.d. molybdenum tube. 
to provide a tube having the desired shape and porosity. Such a tube would be springy, due to its interlocking structure, and might make a good wick.

In an effort to get fibers to start the program, we obtained some discarded, unreacted, niobium-tin superconducting wires, and attempted to dissolve the copper and tin surrounding the filaments to give us very fine (submicrometer diameter) wire. Unfortunately, this wire was not from the very early superconducting experiments, but had the tantalum sheaths that are now used to prevent the tin from migrating throughout the copper stablizing matrix in this material. As a result, the niobium filaments could not be freed from the matrix by dissolution processes.

We are presently attempting to get some niobium-titanium superconducting wire and will proceed with those fibers. An alternative method is to examine felting of tubes with stainless steel fibers. Both may be pursued.

4. Extruded Molybdenum Heat Pipe Wicks (D. Schell, CMB-6). We tried to make a thin tubular wick with the required porosity, using a powder extrusion method with a controlled-size pore former and a fugitive binder.

We were able to modify an existing extrusion die to make it suitable for producing a tube having a 19.3-mm o.d. with a $0.61-\mathrm{mm}$ wall. Extrusions were attempted using a 2.2-um-diam molybdenum powder, carbopol 934, and ethylene glycol, but uneven feeding resulted in a poor extrusion. By enlarging the outer diameter to $20.07-\mathrm{mm}$ diam, which resulted in a $0.99-\mathrm{mm}-$ thick wall, a similar mix was extruded, but the tube collapsed under its own weight upon emerging from the die. The die pin was sheared during this run, which terminated the experiment.

This same mix was extruded through a 12.70-mm-diam die having a 9.14-mmdiam pin, producing a tube with a 1.78-mm-thick wall. The tubes were dried and presintered at $1000^{\circ} \mathrm{C}$ in hydrogen. The diameters of the tubes were 0.25 to $0.38 \mathrm{~mm}$ out of round, suggesting that the tubes sagged while drying. The presintered density was $\sim 34 \%$ of theoretical.

Solving the sagging problem without going to quite a heavy wall thickness would be difficult and time consuming. Approaches would be to look at mix viscosity and different molybdenum powders. However, no further activity is planned at this time. 
D. Facilities (K. L. Meier and L. N. Vikdal, Q-13).

The commercially procured radiant heater, one of two approaches to provide a heat source for long-term heat pipe tests, underwent several tests in a heat pipe vacuum test chamber. Some of the tests were conducted with a sodiumloaded stainless steel heat pipe in place. Power extraction by the heat pipe was a maximum of $5 \mathrm{~kW}$ at $1100 \mathrm{~K}$. During subsequent testing to a total input power of $15 \mathrm{~kW}$, the tungsten heater temperature reached $2600 \mathrm{~K}$ and difficulties were encountered with insulation, multilavered heat shields, and electrical leads. Cracking of the tungsten current-distribution leads that feed the woven tungsten heating elements was also observed.

Although these heaters normally operate in a vertical orientation, the manufacturer's modifications should have allowed horizontal operation at temperatures up to $3300 \mathrm{~K}$. None of the problems encountered would have precluded operation of the heater after repairs had been made. However, the prime impetus behind the radiant heater development was to achieve efficient, reliable, longterm operation. This does not appear to be a characteristic of the present system. In addition, considerable doubt has arisen that the radiant heater $c$ an transfer the required power to a molybdenum heat pipe.

Because of the low heat transfer and the difficulty in increasing it, the low reliability, and the extensive repairs required, radiant heater testing was suspended.

Assembly of additional vacuum test chambers has begun. Two of the 0.4-mdiam, 2.2-m-long chambers will be prepared for both short-and long-duration heat pipe testing. The 30-cm-long molybdenum conduction heaters will be used.

Assembly of the conduction heater has begun. The Semco heater rods have been delivered, inspected, and radiographed. The glass frit seals where the lead wires enter the sheaths, appear satisfactory. Water-cooled, copper, electrical power connectors for the heater rods have been fabricated, and preparation of the water-cooled heat shield is under way.

E. Materials.

1. Molybdenum Heat Pipe Corrosion Studies (L. B. Lundberg, L. A. Geoffrion, Q-13, E. K. Storms, CMB-3). The study of the corrosion of molybdenum heat pipes containing sodium as the working fluid continues as part of an experimental program under way to simulate the thermochemistry of Mo/Na heat 
pipes in a SPAR reactor core environment. This is done by sealing $\mathrm{UO}_{2}$ under vacuum inside a tight-fitting molybdenum or TZM molybdenum alloy capsule, which is, in turn, sealed inside a Mo/Na heat pipe. The wick in the heat pipe is a loosely wrapped, 150 mesh molybdenum screen; the tube containing the $\mathrm{UO}_{2}$ is centered in the heat pipe bore by a mating recess in the center of the blind end cap and by wire supports near the fill end cap.

One heat pipe containing a molybdenum tube filled with $\mathrm{UO}_{2}$ has operated for over $3000 \mathrm{hr}$ at $1475 \mathrm{~K}$ without failure, and another heat pipe containing an empty TZM tube has operated for the same period at $1500 \mathrm{~K}$ without failure. These tests are continuing.

The $\mathrm{UO}_{2}$ from the heat pipe that failed last quarter has been analyzed with a mass spectrometer to determine its $0 / U$ ratio and its oxygen activity. It was found after the test that this sample had $0 / U=1.988 \pm 0.005$, and, consequentiy, it appears that oxygen from the $\mathrm{UO}_{2}$ did not contribute to the failure of this heat pipe. The TZM container tube is being chemically analyzed to determine if it collected oxygen from the $\mathrm{UO}_{2}$.

Six more Mo/Na heat pipes like those described above are ready for filling with sodium. One of these heat pipe assemblies will be a duplicate of the one that failed. It is anticipated that the experimental assemblies like those presently operating will be operated at somewhat higher temperatures to try to produce a failure.

2. Molybdenum-Rhen ium Alloy Development (L.B. Lundberg, Q-13). Attempts to EB-melt Mo-13 wt\% Re alloy ingots at Cabot Corp. have failed because they underestimated the additional heat required to melt this alloy and the inability of the cooling system in their melter to reject it. Consequently, we have decided to vacuum-arc-melt the ingots at 0ak Ridge National Laboratory, with subsequent hot extrusion. This processing should begin shortly.

We have received a piece of SPAR core-heat-pipe-size tubing $0.8 \mathrm{~m}$ long, which was produced by Metallwerk Plansee in Austria from powder metallurgically produced Mo-13Re alloy. This piece of tubing is being evaluated to determine whether its mechanical properties represent a major improvement over either pure molybdenum or TZM, as we expect from the literature search that was published last quarter (LA-8685-MS) and was presented at the 16th AIAA Thermophysics Conference on June 24, 1981. So far, a few simple 
tube-flattening experiments have revealed that the Mo-13Re tubing is much more ductile than either pure molybdenum or TZM. Several heat-treating cycles and aging schedules are presently being applied to samples of this tubing to determine their effects on mechanical properties, especially ductility. Ring tensile tests at room temperature will be used to measure these properties. Chemical analyses are presently under way to verify the values reported by the manufacturer.

\section{RADIATOR DEVELOPMENT}

A. Radiator Heat Pipe Testing (S. P. Girrens, Q-13, and D. Ernst, Thermacore). The 5.5-m titanium heat pipe, RAD-3, was shipped to Thermacore for fill and test. Thermacore has added an extension to their vacuum fill and test chamber to accommodate the heat pipe. A support structure utilizing alumina rods was developed to support and restrain the heat pipe in a level orientation while allowing the heat pipe to grow due to thermal expansion. Thermacore's distillation apparatus was also modified, and will be assembled as shown in Fig. 24. Development is continuing on the rf coil design to input heat into the evaporator. Thermacore has found that titanium does not couple well with rf. Testing of coil configurations is continuing, with the prime candidate a pancake coil with four turns, constructed of 1/8-in. copper tubing.

B. Titanium-Potassium Heat Pipe Corrosion Experiments (L. B. Lundberg, Q-13). Further analyses have been performed on the $\mathrm{Ti} / \mathrm{K}$ heat pipe corrosion samples. The potassium from both samples was chemically analyzed for oxygen by neutron activation methods. It was found that the potassium from the heat pipe that operated at $815 \mathrm{~K}$ contained close to $450 \mathrm{ppm}$, while the potassium from the heat pipe operated at $900 \mathrm{~K}$ was only about $130 \mathrm{ppm}$. The titanium from both heat pipes was also chemically analyzed for carbon, oxygen, and nitrogen; there was no significant change in the concentration of these elements relative to the starting material.

Metallographic examination of the region of the heat pipe wall that was in contact with the copper heater block revealed that only in the case of the 


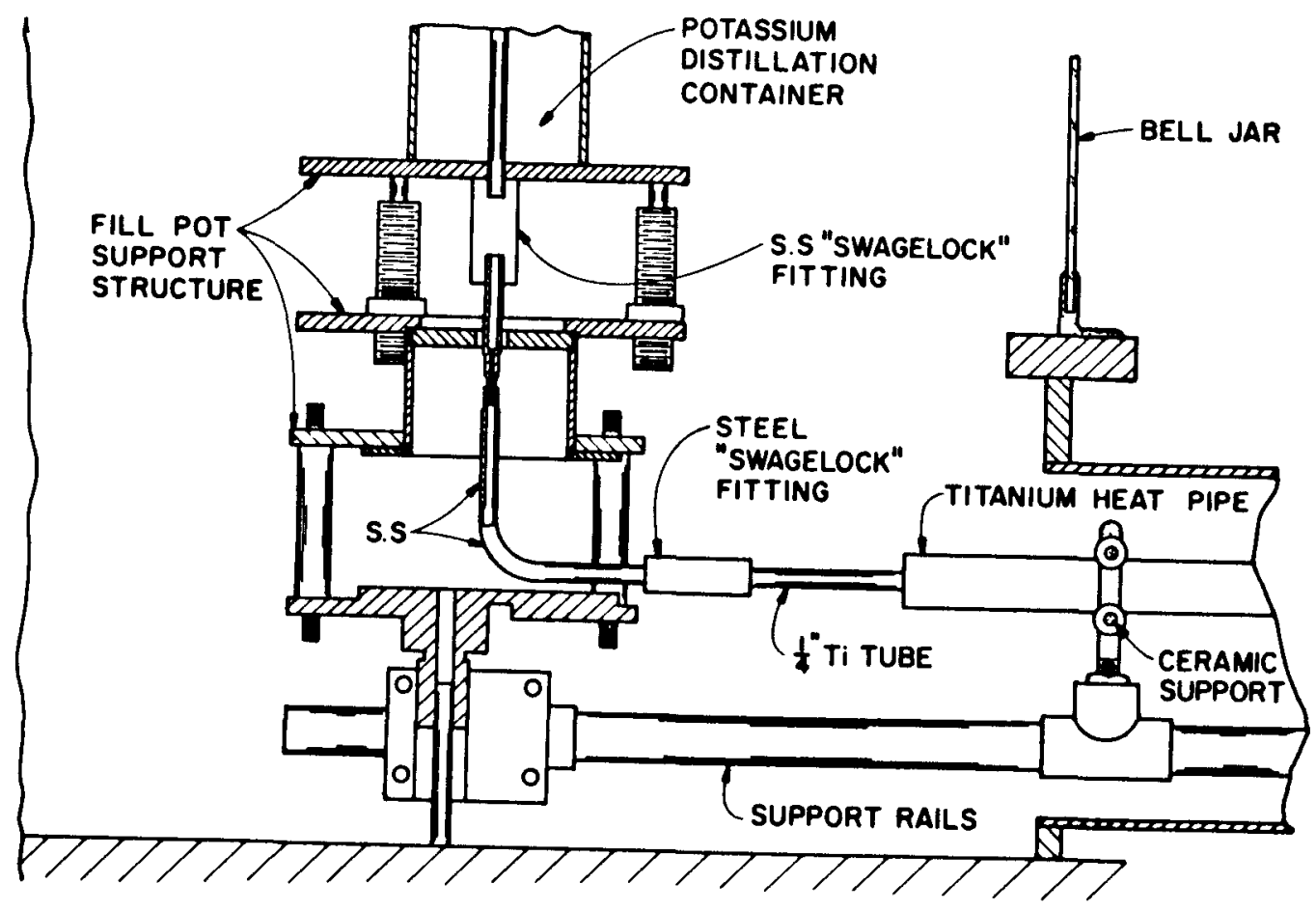

Fig. 24. Thermacore heat pipe distillation fill assembly.

$815 \mathrm{~K}$ experiment was there evidence of copper diffusion completely through the heat pipe wall. It is clear from these examinations that the copper heater blocks should be replaced with titanium in future experiments.

VI. THERMOELECTRIC MODULE DEVELOPMENT (G. W. Fly, Q-13, and V. Raag, Syncal)

A. Material Development.

The annealing studies of SiGe-GaP specimens have been completed, with very little change in the room-temperature electrical properties over the last $3000 \mathrm{hr}$. These tests show that the material approaches a stable condition, because most of the change in electrical properties occurred in the first 1500 $2000 \mathrm{hr}$. These tests also show that the percentage change in overall electrical properties, as measured by $s^{2} / \rho$, is significantly less for galliumphosphide-enhanced silicon-germanium than for the standard silicon-germanium material. 
B. Thermocouple Design and Fabrication.

A thermocouple design was completed with essentially the same geometry as the ring module design done last December. Some minor modifications were made to facilitate testing, but these changes do not significantly affect the thermocouple performance. Consequently, the results of the thermocouple tests should be directly applicable to the design of a ring module.

A series of tests have been completed to evaluate the bonding at each interface in the proposed thermocouple. These tests have shown that the bonding layouts and processing parameters provide good metallurgical bonds at each interface, and that the strengths of the adjacent materials are sufficient to withstand the stresses imposed by the variations in thermal expansion coefficients. Preliminary metallographic analys is of these interfaces indicates that the bonding is complete and uniform at each interface.

The thermocouple is attached to a separate heater base, rather than mounted on a heat pipe. This allows easier evaluation of the input power and hot side heat fluxes. The heater consists of molybdenum wire encased in a ceramic coating around the heater base. This heater can provide several hundred watts input to the thermocouple. Heat rejection on the cold side is through radiation from a silicon-nitride-coated niobium sheet.

The entire thermocouple is set up like a comparative thermal conductivity apparatus to minimize radial heat losses. An outer foil, which connects the hot and cold sides, maintains a temperature profile similar to that through the thermocouple. The space between the thermocouple and the foil is filled with alumina powder to minimize the radiation interaction. The thermocouple is then extensively instrumented with 19 tungsten-niobium thermocouples to provide interface temperature-drop data.

All of the components for the thermocouples have been fabricated, and the initial assembly procedures have been completed. Final assembly of the thermocouple is currently being done at syncal.

\section{Testing.}

A vacuum chamber has been constructed for testing the thermocouples. The chamber can handle up to 30 thermocouple feedthroughs, with separate input and output power feedthroughs. Adjustable radiation shields are provided to control the cold side heat rejection from the thermocouple. The data acquisition 
system has also been completed. A Hewlett Packard 3052 data acquisition system, which has been set up with a 50-channel capability, has been connected to the chamber. The data acquisition and reduction programs have been set up and checked out. The system can sample at rates as high as 10 samples per second in this configuration, and up to $8 \mathrm{hr}$ of data can be stored in a stand-alone mode. The data rates and storage times are configurable.

The chamber has been set up with pin connector attachments to the feedthroughs to allow quick removal and installation of the silicon-germanium thermocouples. This will provide quick turnaround capability for modifications to the thermocouples during this testing and development program.

D. Insulators.

Aluminum nitride power with less than $50 \mathrm{ppm}$ carbon was obtained from Cerac Pure, Inc. This material was chemically analyzed to verify the purity. A compact of AlN was hot-pressed in a tantalum-sleeved graphite die. The compact was slightly discolored, indicating some contamination. It was sliced, and one of the slices was submitted for wet chemical analysis. A compact of $15 R$ Sialon is presently being prepared using the same procedure.

Furnaces for the insulator testing program have been received, and are currently being wired in and checked out. The 5-in-diam alumina tubes that will form the hot end of the vacuum chamber for these furnaces have been received, and the stainless steel chambers that attach to the alumina tubes and provide feedthroughs and vacuum connections are currently being fabricated. 